Article

\title{
Exploring the Microbial Dynamics of Organic Matter Degradation and Humification during Co-Composting of Cow Manure and Bedding Material Waste
}

\author{
Haiyan Duan 1,2,3, Minghua Ji 1,3, Yukang Xie 1,3, Jiping Shi 1,2,3, Li Liu 1,3,4, Baoguo Zhang 1,3,*(D) \\ and Junsong Sun $1,2,3, *$
}

1 Laboratory of Biorefinery, Shanghai Advanced Research Institute, Chinese Academy of Sciences, No. 99 Haike Road, Pudong, Shanghai 201210, China; duanhaiyan@sari.ac.cn (H.D.); jimh@sari.ac.cn (M.J.); xieyukang2018@sari.ac.cn (Y.X.); shijp@sari.ac.cn (J.S.); liul@sari.ac.cn (L.L.)

2 School of Life Science and Technology, Shanghai Tech University, Shanghai 201210, China

3 University of Chinese Academy of Sciences, Beijing 100049, China

4 China Shanghai Engineering Research Center of Biotransformation of Organic Solid Waste, Shanghai 200241, China

* Correspondence: zhangbg@sari.ac.cn (B.Z.); sunjs@sari.ac.cn (J.S.)

Citation: Duan, H.; Ji, M.; Xie, Y.; Shi, J.; Liu, L.; Zhang, B.; Sun, J. Exploring the Microbial Dynamics of Organic Matter Degradation and Humification during Co-Composting of Cow Manure and Bedding Material Waste. Sustainability 2021, 13, 13035. https://doi.org/10.3390/su132313035

Academic Editor: Domenico Ronga

Received: 26 October 2021

Accepted: 20 November 2021

Published: 25 November 2021

Publisher's Note: MDPI stays neutral with regard to jurisdictional claims in published maps and institutional affiliations.

Copyright: (c) 2021 by the authors. Licensee MDPI, Basel, Switzerland. This article is an open access article distributed under the terms and conditions of the Creative Commons Attribution (CC BY) license (https:/ / creativecommons.org/licenses/by/ $4.0 /)$.

\begin{abstract}
The present study investigated the effects of bedding material (BM) waste on physicochemical properties, organic matter (OM) degradation, microbial community structure and metabolic function during composting. The results showed that bedding material (CK-0, S1-40\%, S2-25\%) optimized the composting conditions for lignocellulose and OM biodegradation. The highest OM degradation and humic substance (HS) synthesis rates were observed in the $40 \%$ BM addition group. Firmicutes was more abundant in the bedding material addition groups, whereas Proteobacteria was more abundant in the group without bedding material. Functional prediction showed higher carbohydrate and amino acid metabolism in the BM groups than that in control group. Animal and plant pathogens were almost eliminated, and saprotrophs were the dominant fungal trophic modes after $40 \% \mathrm{BM}$ addition composting. Cellulose, hemicellulose, and organic matter had strong associations with microbial communities, such as Lysinibacillus and Corynebacterium (bacteria), compared to the associations of Aspergillus, Candida, and Sordariomycetes (fungi) ( $p$ value $<0.05$ ). Network analysis revealed closer microbial community interactions in 40\% BM addition group than in other groups. These findings provide detailed information about the coupling of material conversion, of bacterial and fungal succession during composting, and that bedding materials waste can also be used as an effective compost amendment.
\end{abstract}

Keywords: cow manure composting; waste bedding material; organic matter; humification; bacterial and fungal community; metabolism

\section{Introduction}

Livestock production accounts for approximately $40 \%$ of the global value of agricultural products and employs almost 1.3 billion people worldwide [1]. However, it also raises concerns about substantial manure generation [1]. More than half of the total manure generated from all livestock is cow manure (CM). Approximately 380 million tons of CM are generated annually in China, mostly from centralized large-scale farms [2]. CM contains various hazardous components and pathogens, and the improper handling of CM poses threats to soils, crops, and human health, and causes water and air environmental pollution to the surroundings [3,4]. Biomass bedding is another popular technology in the livestock industry, especially in the cow dairy industry, which provides a comfortable lying surface for animals on farms [5,6]. A large amount of bedding material (BM), such as rice husks and wheat straw, is often used to construct the bedding layer $[7,8]$. Consumed $\mathrm{BM}$ typically must be disposed of annually or biennially, and BM contains a large amount 
of biomass. Therefore, methods to effectively use these materials, and to thus achieve resource recycling instead of discarding, have not been explored. Recent limited efforts were made to investigate appropriate treatment methods [9].

Composting is a microorganism-mediated technology with high efficiency for converting various degradable organic matter $(\mathrm{OM})$ into humus-like substances. Notably, the composting process is dramatically affected by various composting factors (temperature and $\mathrm{pH} \mathrm{C/N}$ ratio, etc.) $[10,11]$. Dissolved organic matter (DOM) is an available energy resource for microbiota, and it reflects compost stability and maturity [12]. Composting products may be further used to improve the physical properties of soil $[13,14]$. Some studies showed enhanced composting processes of livestock manure when amended with additive materials, such as wood shavings, sawdust, and cornstalks, because these diverse additives altered the physiochemical properties of feedstock to a more appropriate level [15-17]. The major components of organic wastes include carbohydrates, such as lignocellulosic and proteinaceous substances. Mesophilic and thermophilic bacteria perform the degradation activities of organic wastes, and fungi participate in the composting process due to the abilities of different functional enzyme production and the decomposition of various compounds $[18,19]$. Although many studies focused on bacterial dynamics during multiple composts and bacterial structures at specific composting timepoints $[2,10,20]$, the influence of fungi on composting has not received sufficient attention. Due to recent advancements in sequencing technology, studies that attach importance to the key role of fungal dynamics in OM transformation during composting have become increasingly detailed (Duan et al., 2019). However, confirmation of the functional microorganisms and critical evidence from in situ studies related to microbial conversion of agricultural waste remain elusive, especially with respect to fungi. Knowledge of BM waste as a compost amendment remains insufficient, and there is no understanding of how BM performance and microbial mechanisms occur during composting.

The present study investigated the composting performance of BM waste additives to cow manure compost, especially on OM biodegradation and the dynamics and metabolic function profiles of bacterial and fungal communities. The present study (1) explored the effect of BM as an additive on the physicochemical properties of compost and mature compost, (2) investigated the BM effect on bacterial and fungal structural changes and metabolic succession, and (3) assessed the correlation between bacterial and fungal dynamics and various physicochemical properties during composting.

\section{Materials and Methods}

\subsection{Composting Process and Sampling}

Cow manure (obtained after dewatering fresh cow manure), wheat straw (WS) and BM waste were collected from the research farm at Jixiang Livestock Co., Ltd., Fujian, China and used as feedstock for composting. Table 1 shows the basic properties of these materials. CM was mixed with 3-5 cm WS $(2: 1, w / w)$ before BM waste addition. A total of three different treatments were performed: blends with $40 \%$ BM waste $(\mathrm{S} 1, w / w)$, blends with $25 \% \mathrm{BM}$ waste $(\mathrm{S} 2, w / w)$, and treatment without any additives $(\mathrm{CK})$. The $\mathrm{C} / \mathrm{N}$ ratio was adjusted with the application of urea, which was used as an inorganic nitrogen source [10]. The composting C/N and water content were controlled between $30 \%$ and $70 \%$, respectively [21]. After thoroughly mixing the raw materials using a mechanized mixer, the composting piles were established in a pyramid shape of approximately $3 \mathrm{~m} \times 3 \mathrm{~m} \times 1.5 \mathrm{~m}$ (length $\times$ width $\times$ height). Each pile was turned using a forklift every 5 days. The composting lasted for 60 days. Each treatment was performed in triplicate. Compost samples were collected on days $0,3,7,15,20,30,40$, and 50 of composting. The subsamples were taken from different positions, the top ( $30 \mathrm{~cm}$ from the top), middle, and bottom (30 $\mathrm{cm}$ from the bottom) of the piles (approximately $1 \mathrm{~kg}$, wet weight). Collected sub-samples were mixed to form a composite sample. Each sample was divided into 2 parts: 1 part was used for the analysis of physiochemical parameters, and the other part was stored at $-20.0^{\circ} \mathrm{C}$. According to the temperature change, samples in the initial phase 
(day 0), mesophilic phase (day 7), thermophilic phase (day 20), cooling phase (day 40), and maturation phase (day 60) were used for microbial community analyses.

Table 1. The compositions of the raw materials.

\begin{tabular}{ccccccc}
\hline Materials & Moisture (\%) & pH & OM (\%) & TOC (\%) & TKN (\%) & C/N \\
\hline WS & $8.7 \pm 1.7$ & $6.63 \pm 0.05$ & $71.1 \pm 2.3$ & $41.1 \pm 1.1$ & $0.17 \pm 0.01$ & $24.2 \pm 0.5$ \\
CM & $61.6 \pm 1.9$ & $7.92 \pm 0.07$ & $87.2 \pm 2.1$ & $39.9 \pm 1.5$ & $1.37 \pm 0.02$ & $29.1 \pm 0.3$ \\
BM & $54.4 \pm 1.6$ & $8.84 \pm 0.06$ & $79.3 \pm 2.4$ & $49.3 \pm 1.8$ & $2.21 \pm 0.01$ & $22.3 \pm 0.2$ \\
\hline
\end{tabular}

Note: Values indicate the means \pm standard deviation based on determination with 3 replications. CM: cow manure; WS: wheat straw; BM: bedding material waste; OM: organic matter; TOC: total organic carbon; TKN: total Kjeldahl nitrogen; $\mathrm{C} / \mathrm{N}$ : carbon: nitrogen ratio.

\subsection{Physicochemical Analysis}

The temperature was recorded at 5 sites $(30-50 \mathrm{~cm})$ of the piles before mixing. The water content was obtained by measuring the weight loss by drying the samples at $105^{\circ} \mathrm{C}$ for $24 \mathrm{~h}$. The contents of $\mathrm{OM}$ were measured at $550{ }^{\circ} \mathrm{C}$ for $5 \mathrm{~h}$ [22]. The dried samples were crushed and passed through a $0.25-\mathrm{mm}$ sieve. The $\mathrm{pH}$ was measured after mixing each sample with distilled water $(1: 10, w / w)$. The total organic carbon (TOC) and total Kjeldahl nitrogen (TKN) were measured using the Kjeldahl method, and the $\mathrm{C} / \mathrm{N}$ was calculated accordingly $[11,23]$. The germination index (GI) was tested using the methods in a previous report [24].

A total of five grams of dried compost from each sample was extracted with $50 \mathrm{~mL}$ deionized water for $24 \mathrm{~h}$ at $25^{\circ} \mathrm{C}$, and the aqueous extract was harvested via centrifugation at 10,000 rpm for $10 \mathrm{~min}$ and filtration through a $0.45-\mathrm{mm}$ membrane filter. Fluorescence measurements were performed on the aqueous extract using an F-7000 (Hitachi, Japan) spectrometer equipped with a xenon excitation source. To obtain the fluorescence spectra of the EEM (excitation emission matrix spectra), the excitation wavelengths were increased from 220 to $450 \mathrm{~nm}$ in 5-nm steps, and the emission wavelengths were detected from 280 to $550 \mathrm{~nm}$ in 2-nm steps [12].

The contents of lignocellulose (cellulose, hemicellulose, and lignin) were measured using a previously described method [25], and their degradation rates were calculated using the formula

$$
T n=(S 0-S n) / S 0 \times 100 \%
$$

where $T n, S n$ and $S 0$ represent the lignocellulose biodegradation rate on the nth day, the content on the nth day, and the content on day 0, respectively [25].

All physicochemical parameters used for analyses were assessed in triplicate.

\subsection{DNA Extraction and High-Throughput Sequencing}

Total DNA was extracted using an E.Z.N.A. ${ }^{\circledR}$ soil DNA Kit (Omega Bio-Tek, Norcross, GA, USA). The concentration of extracted DNA was determined using a NanoDrop ND-2000 spectrophotometer (Thermo Fisher Scientific, Wilmington, NC, USA). All DNA extracts were stored at $-80{ }^{\circ} \mathrm{C}$ until use. The variable V3-V4 region of the 16S rRNA gene was selected for MiSeq sequencing using the barcoded fusion primers 338F (ACTCCTACGGGAGGCAGCAG) and 806R (GGACTACHVGGGTWTCTAAT) [2]. ITS1-F (TTGGTCATTTAGAGGAAGTAA) and ITS2-R (GCTGCGTTCTTCATCGATGC) were used to amplify the ITS region for fungal analyses [26]. PCR was guided using a previously described procedure [2]. PCR products were sent to Majorbio Biopharm Technology Co., Ltd. (Shanghai, China) for subsequent analysis as described in a previous study [26].

\subsection{DNA Extraction and High-Throughput Sequencing}

Raw gene sequence data generated from the Illumina sequencing were imported into Trimmomatic and FLASH software for data modification. The sample sequence was flattened by the minimum sample sequence number. Usearch 7.1 (http:/ / qiime. org/, accessed on 26 May 2021) was used to cluster the sequences into operational 
taxonomic units (OTUs) with 97\% pairwise identity in QIIME (http://qiime.org/, accessed on 26 May 2021). The Ribosomal Database Project classifier (Release $11.1 \mathrm{http}$ : //rdp.cme.msu.edu/, accessed on 2 May 2020) was used for taxonomic classification of the representative sequences of bacteria against the Greengenes 16S rRNA database (Release 13.5, http:/ / greengenes.secondgenome.com/, accessed on 2 May 2020) and the Silva database (release 138.1, http:/ / www.arb-silva.de, accessed on 29 May 2021). The fungal taxonomic classification was based on the fungal UNITE ITS 12_11 database (release 5.0, http:/ / unite.ut.ee/index.php, accessed on 2 June 2021). The taxonomic information for the 35 most abundant OTUs was uploaded to the FUNGuild database (http:/ / www.stbates.org/guilds/app.php, accessed on 2 June 2021) for functional prediction, and their sequences were aligned using PhyDE (Phylogenetic Data Editor). Manual adjustments were made to the alignment where necessary [27]. The neighbor-joining trees were constructed using MEGA version 6.0 (http:/ / megasoftware.net, accessed on 6 June 2021) with 1200 bootstrap replicates. The bacterial OTUs were imported into PICRUSt, which demonstrated that the genome prediction accuracy was $>0.80$. The metabolic pathways were analyzed using the Kyoto Encyclopedia of Genes and Genomes (KEGG) module after normalizing the OTU table. CANOCO 5 software was used to assess the correlations between microbial communities and environmental factors. The correlation between the bacterial community and environmental factors was analyzed using redundancy analysis (RDA) or canonical correspondence analysis (CCA) in the R language vegan package.

\section{Results and Discussion}

\subsection{Changes in Physicochemical Characteristics during Composting}

Physicochemical characteristics generally act as vital factors during the composting process that largely affect the performance and products of the compost [21]. The dynamics of the key physicochemical characteristics during the composting process are shown in Figure 1 and Table 2. Temperature is generally considered the most important factor, and it affects composting efficiency during the decomposition of $\mathrm{OM}$ by increasing or decreasing microbial activities [28,29]. The temperature of the $\mathrm{S} 1$ group quickly increased to $45^{\circ} \mathrm{C}$, entering the mesophilic phase $\left(45-55^{\circ} \mathrm{C}\right)$ after 3 days of incubation, which was faster than CK and S2 groups $(p<0.05)$ because the diverse, easily degradable substances (e.g., carbohydrates and proteins) decomposed rapidly, exhibiting substantial heat loss [30]. After that, all the treatments subsequently started the thermophilic mode $\left(>55^{\circ} \mathrm{C}\right)$; among these groups, the thermophilic stage was maintained for 9 days in the CK treatment, and significantly less than 25 days in S1 and 17 days in S2 $(p<0.05)$, respectively. S1 quickly reached the highest temperature $\left(64.3^{\circ} \mathrm{C}\right)$ on day 20 among the three treatments $(p<0.05)$, compared with the other two groups. Then, there was a cooling and maturation stage $\left(<55^{\circ} \mathrm{C}\right)$, during which the temperature gradually decreased to approximately $36-40{ }^{\circ} \mathrm{C}$ after composting. These results likely indicated that the addition of $40 \%$ bedding material could effectively increase the composting thermophilic temperature, maintain the composting temperature, and then shorten the whole composting time.

The water content of the S1 group decreased the fastest, from 70 to $55 \%$, during the thermophilic phase, because of the sharp change in temperature, and it then gradually stabilized to approximately $50 \%$ in the cooling and mature stages (Figure 1b). In Figure 1c, the $\mathrm{pH}$ of the three treatments exhibited alkaline environments during the composting process. In Figure 1c, the $\mathrm{pH}$ showed an increasing trend early, which is likely because of the decomposition of small molecular acidic substance and the gradual mineralization of organic matter by microbial metabolism, causing the release of ammonium nitrogen $\left(\mathrm{NH}_{4}{ }^{+}-\mathrm{N}\right)$ and $\mathrm{NH}_{3}$ [31]. As the effect of ammonification decreased, the slowing $\mathrm{NH}_{3}$ volatilization and $\mathrm{CO}_{2}$ dissolved, showing acidity, and leading to the low and stable $\mathrm{pH}$. In Table 2, a higher $\mathrm{pH}$ during composting was consistently found in the BM-adding treatments, rather than in the control group $(p<0.05)$, probably because the bedding material could significantly affect the acid-base balance in the composting. Most likely due to the addition of inorganic nitrogen sources, the $\mathrm{pH}$ of $\mathrm{S} 2$ was always higher than $\mathrm{S} 1$ 
during the mesophilic and thermophilic stage $(p<0.05)$. The final $\mathrm{pH}$ values of $\mathrm{S} 1(8.35)$, S2 (8.21) and CK (8.44) met the requirement for maturity (7.0-8.5) [32]. In Figure 1d, the contents of TOC in the three treatments showed a downward trend because of the aerobic degradation of macromolecules and the rapid loss of $\mathrm{CO}_{2}$. The contents significantly and sharply decreased on day 20 , by $54.6 \%$ in S1, by more than $26.1 \%$ in S2, and $12.2 \%$ in CK $(p<0.05)$. The greatest decrease of TOC in S1 may have been due to the rapidly increasing temperature, probably increased by thermophilic microbiota (Section 3.3), thus possibly further promoting TOC degradation. For example, some studies show that compost with a psychrotrophic-thermophilic complex microbial agent inoculation can accelerate various microbial activities, which accounts for the decrease of TOC, and that inoculation with Pichia kudriavzevii RB1 also accelerates the degradation of TOC during composting [33,34]. There was no significant difference in TOC contents after day $20(p>0.05)$, which indicated that the TOC level eventually stabilized in the cooling and mature phase, likely because the microorganisms started to use lignin and other difficult-to-decompose substances after consuming the readily decomposable substances in the compost material (Section 3.2). However, the final TOC content of S1 $\left(250.5 \mathrm{~g} \cdot \mathrm{kg}^{-1}\right)$ was lower than CK $\left(341.3 \mathrm{~g} \cdot \mathrm{kg}^{-1}\right)$ and S2 $\left(291.3 \mathrm{~g} \cdot \mathrm{kg}^{-1}\right)$ groups $(p<0.05)$. These results demonstrated that $40 \% \mathrm{BM}$ probably markedly accelerated the degradation of TOC during composting.

Figure 1e shows that the TN content in the three treatments exhibited a decrease in the 1st week of composting, which was caused by the rapid decomposition of proteins, following the generation of $\mathrm{NH}_{4}{ }^{+}-\mathrm{N}$ and the loss of $\mathrm{NH}_{3}$ [31]. Significantly higher increases which occurred later were more often found in BM treatments than in CK $(p<0.05)$, and the $\mathrm{TN}$ content was 1.71 in S1, which was higher than 1.45 in S1 and 1.41 in S2 $(p<0.05)$ at the end of composting. It is likely that this result occurred because the rapid TOC degradation rate was higher than the nitrogen loss rate, which resulted in an increase in nitrogen content per unit mass [35]. A similar study confirmed that the TN content which increased during composting occurred because of the TOC reduction and the nitrogen-fixing bacterial function [36]. Throughout the entire composting process, the $\mathrm{C} / \mathrm{N}$ of all the treatments showed a decreasing trend (Figure $1 \mathrm{f}$ ). When composting was finished, the $\mathrm{C} / \mathrm{N}$ ratio was 12.7 in S1 compared to 22.4 in CK and 17.4 in S2 $(p<0.05)$, which demonstrated that $40 \%$ $\mathrm{BM}$ addition compost products had a higher degree of maturity.

A GI value greater than $80 \%$ generally acts as a vital index to evaluate whether compost is mature and non-phytotoxic [32]. During the composting process, the GI value continued to increase, and the values of S1 $(123.1 \%)$ and S2 $(91.8 \%)$ met the standard of a mature compost product and were significantly higher than the CK group (57.4\%) $(p<0.05)$, which was too low to be satisfactory (Figure 1 g, Table 2$)$. The $40 \%$ BM addition group increased the GI value by $51 \%$ compared to the CK group. According to the analysis of physicochemical characteristics, the addition of BM to compost, especially $40 \%$ BM, was an effective method to obtain a more mature compost compared to other treatments in this study.

\subsection{Degradation of OM and Formation of HS}

Table 3 and Figure 2 show the degradation of OM and formation of humic substances in the different composting systems. As composting proceeded, the OM content of the three treatments continuously decreased, which was likely due to the rapid transformation of microorganisms from OM to stable HS [37]. The OM degradation of S1 was always higher than CK after 7 days of composting $(p<0.05)$, and the final rates of S1 were $10.1 \%$, which was higher than $7.7 \%$ in CK and $8.2 \%$ in S2 $(p<0.05)$, respectively (Table 2 and Figure S1). This result likely occurred because the $\mathrm{BM}$ created better conditions for the related microbiota growth, which enhanced the microbial interactions with the OM degradation. 

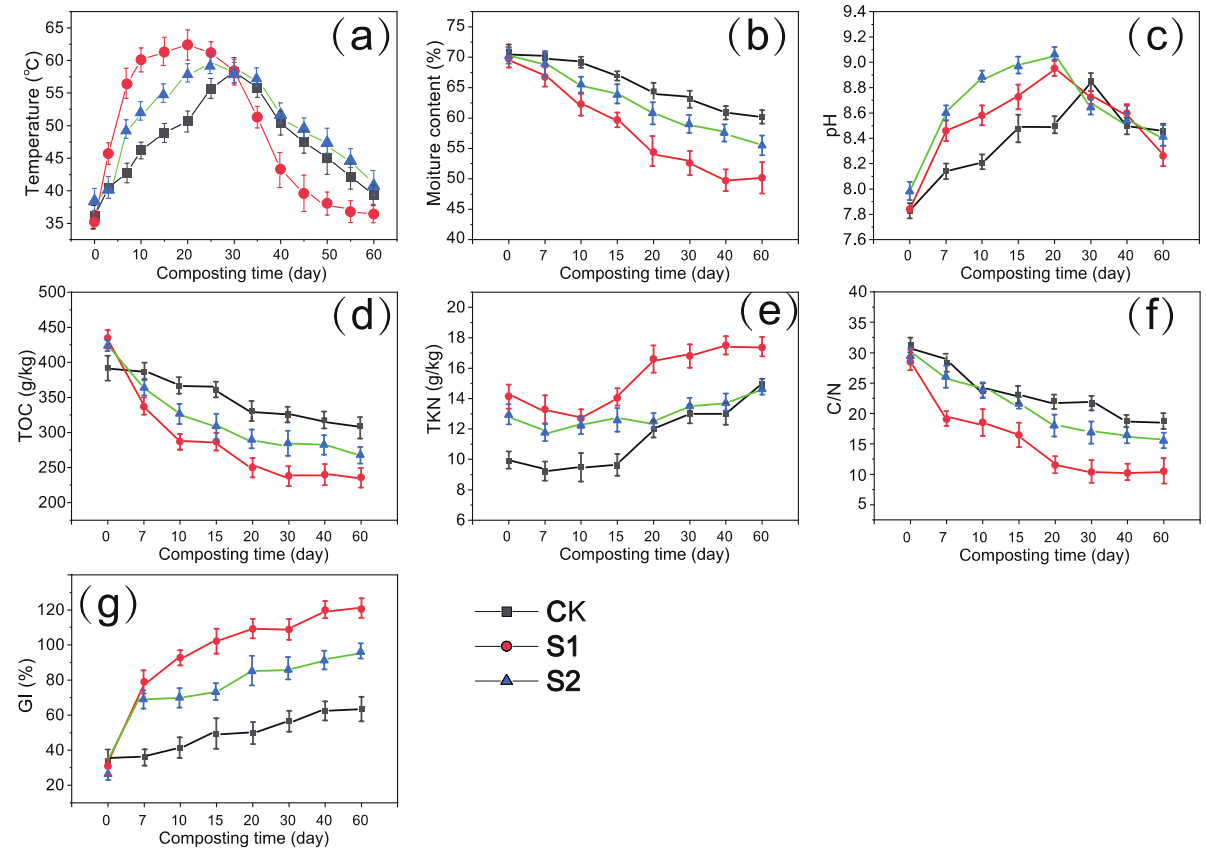

$-\mathrm{CK}$

- $\mathrm{S} 1$

$\triangle-\mathrm{S} 2$

Figure 1. Changes in physicochemical parameters during the composting process in response to different treatments. (a) Temperature, (b) moisture, (c) $\mathrm{pH}$, (d) total organic carbon (TOC) concentration, (e) total Kjeldahl nitrogen $(\mathrm{TKN})$ concentration, $(\mathbf{f})$ carbon nitrogen ratio $(\mathrm{C} / \mathrm{N})$, and $(\mathrm{g})$ germination index (GI) (CK-no bedding material addition treatment; S1-40\% bedding material addition treatment; S2-25\% bedding material addition treatment).

Table 2. Physicochemical characteristics during composting.

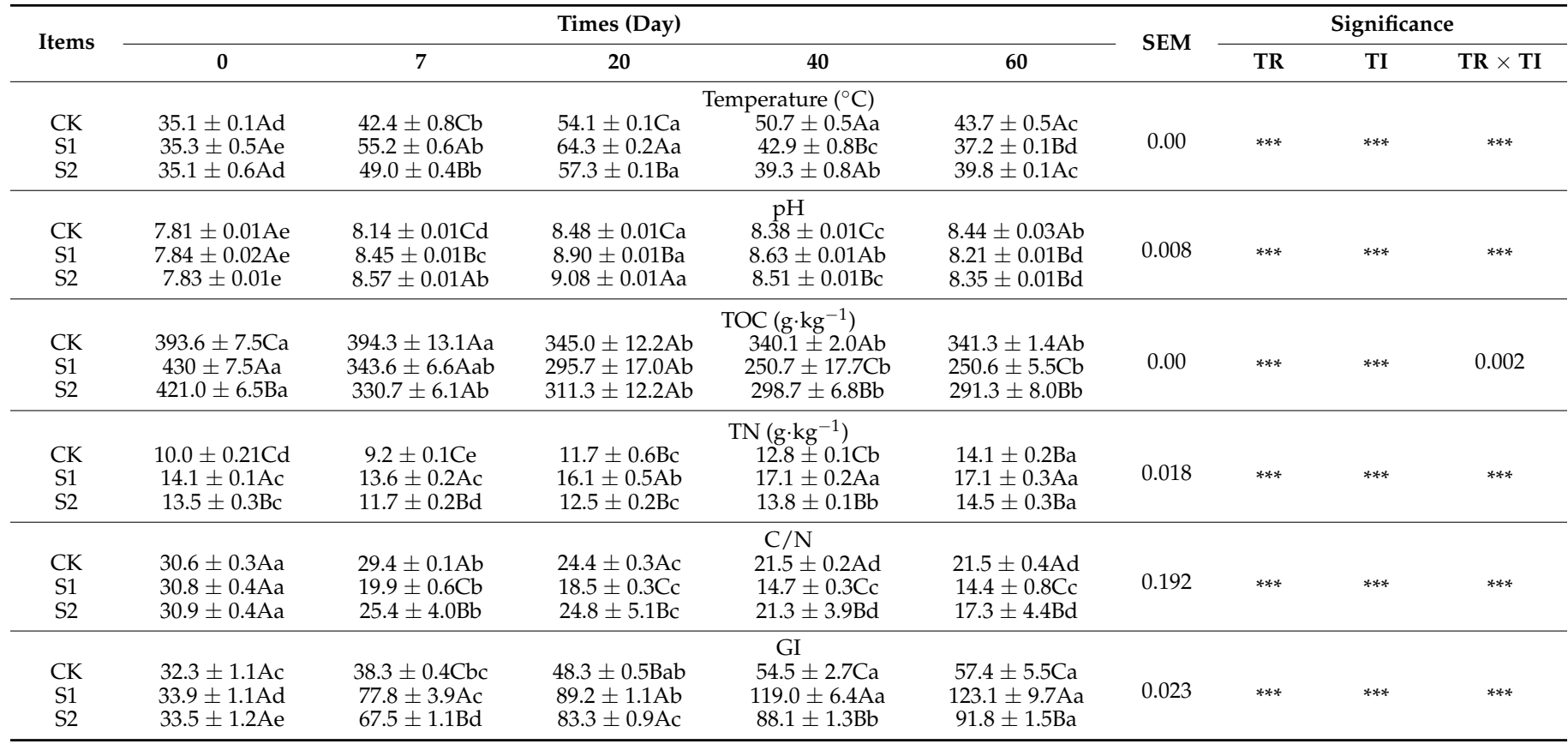

TOC: Total organic carbon; TKN: Total Kjeldahl nitrogen; C/N: Carbon: nitrogen ratio. GI: Germination index. Lowercase letters indicate significant differences between the different composting times $(p<0.05)$. Capital letters indicate significant differences between the CK, $\mathrm{S} 1$ and S2 treatments on the same sampling day $(p<0.05)$. The values are shown as the mean \pm standard deviation of three replicates. SEM: standard error of means. TR: Treatment; TI: Time; TR $\times$ TI: The interaction between treatment and treatment; ${ }^{* * *}: p<0.001$. (CK-no bedding material addition treatment; S1-40\% bedding material addition treatment; S2-25\% bedding material addition treatment). 
Table 3. Degradation of organic matter and lignocellulose.

\begin{tabular}{|c|c|c|c|c|c|c|c|c|c|}
\hline \multirow{2}{*}{ Items } & \multicolumn{5}{|c|}{ Times (Day) } & \multirow{2}{*}{ SEM } & \multicolumn{3}{|c|}{ Significance } \\
\hline & 0 & 7 & 20 & 40 & 60 & & TR & TI & $\mathrm{TR} \times \mathrm{TI}$ \\
\hline \multicolumn{10}{|c|}{ OM (organic matter, \%) } \\
\hline CK & $83.3 \pm 17.6 \mathrm{Aa}$ & $82.1 \pm 6.0 \mathrm{Aa}$ & $78.2 \pm 4.6 \mathrm{Ab}$ & $77.4 \pm 10.5 \mathrm{Ab}$ & $76.6 \pm 3.0 \mathrm{Ac}$ & & & & \\
\hline S1 & $84.7 \pm 17.4 \mathrm{Aa}$ & $82.3 \pm 10.7 \mathrm{Ab}$ & $77.5 \pm 15.5 \mathrm{Ac}$ & $76.9 \pm 16.1 \mathrm{Bcd}$ & $75.2 \pm 10.5 \mathrm{Bd}$ & 0.00 & 0.403 & $* * *$ & 0.315 \\
\hline $\mathrm{S} 2$ & $80.7 \pm 6.9 \mathrm{Ab}$ & $82.1 \pm 3.5 \mathrm{Aa}$ & $78.3 \pm 8.7 \mathrm{Ac}$ & $77.2 \pm 10.3 \mathrm{ABc}$ & $75.7 \pm 5.2 \mathrm{ABd}$ & & & & \\
\hline \multicolumn{10}{|c|}{ Cellulose (\%) } \\
\hline CK & 0 & $12.1 \pm 1.2 \mathrm{Bbc}$ & $15.6 \pm 4.1 \mathrm{Aa}$ & $13.3 \pm 1.4 \mathrm{Ab}$ & $11.6 \pm 1.0 \mathrm{Bc}$ & \multirow{3}{*}{0.056} & \multirow{3}{*}{$* * *$} & \multirow{3}{*}{$* * *$} & \multirow{3}{*}{0.002} \\
\hline $\mathrm{S} 1$ & 0 & $14.3 \pm 1.0 \mathrm{Ab}$ & $16.7 \pm 1.5 \mathrm{Aa}$ & $14.3 \pm 1.0 \mathrm{Ab}$ & $14.3 \pm 6.0 \mathrm{Ab}$ & & & & \\
\hline $\mathrm{S} 2$ & 0 & $11.8 \pm 0.6 \mathrm{Bc}$ & $15.4 \pm 1.0 \mathrm{AaB}$ & $13.8 \pm 1.3 \mathrm{Aab}$ & $12.5 \pm 0.5 \mathrm{Bbc}$ & & & & \\
\hline \multicolumn{10}{|c|}{ Hemicellulose (\%) } \\
\hline CK & 0 & $18.4 \pm 0.5 \mathrm{Ac}$ & $38.2 \pm 1.2 \mathrm{Ba}$ & $40.4 \pm 1.2 \mathrm{Ba}$ & $32.1 .1 \pm 1.1 \mathrm{Bb}$ & \multirow{3}{*}{0.068} & \multirow{3}{*}{$* * *$} & \multirow{3}{*}{$* * *$} & \multirow{3}{*}{$* * *$} \\
\hline S1 & 0 & $20.3 \pm 1.0 \mathrm{Ab}$ & $45.7 \pm 2.5 \mathrm{Aa}$ & $46.6 \pm 2.3 \mathrm{Aa}$ & $42.8 \pm 3.0 \mathrm{Aa}$ & & & & \\
\hline $\mathrm{S} 2$ & 0 & $18.3 \pm 1.2 \mathrm{Ac}$ & $36.3 \pm 0.9 \mathrm{Bb}$ & $42.2 \pm 1.3 \mathrm{Ba}$ & $34.2 \pm 1.1 \mathrm{Bb}$ & & & & \\
\hline \multicolumn{10}{|c|}{ Lignin (\%) } \\
\hline CK & 0 & $4.5 \pm 0.01 \mathrm{Cc}$ & $11.9 \pm 0.18 \mathrm{Bb}$ & $16.1 \pm 0.8 \mathrm{Ba}$ & $12.5 \pm 0.7 \mathrm{Bb}$ & \multirow{3}{*}{0.024} & \multirow{3}{*}{$* * *$} & \multirow{3}{*}{$* * *$} & \multirow{3}{*}{0.002} \\
\hline S1 & 0 & $6.4 \pm 0.1 \mathrm{Ac}$ & $14.5 \pm 0.6 \mathrm{Ab}$ & $20.2 \pm 1.6 \mathrm{Aa}$ & $16.4 \pm 0.7 \mathrm{Ab}$ & & & & \\
\hline $\mathrm{S} 2$ & 0 & $5.4 \pm 0.8 \mathrm{Bc}$ & $13.3 \pm 0.6 \mathrm{ABb}$ & $17.8 \pm 1.3 \mathrm{ABa}$ & $13.4 \pm 0.9 \mathrm{Bb}$ & & & & \\
\hline
\end{tabular}

OM: Organic matter; lowercase letters indicate significant differences between the different composting times $(p<0.05)$. Capital letters indicate significant differences between the CK, S1 and S2 treatments on the same sampling day $(p<0.05)$. The values are shown as the means \pm standard deviation of three replicates. SEM: standard error of means. TR: Treatment; TI: Time; TR $\times$ TI: The interaction between treatment and treatment; ${ }^{* * *}: p<0.001$. (CK-no bedding material addition treatment; S1-40\% bedding material addition treatment; S2-25\% bedding material addition treatment).
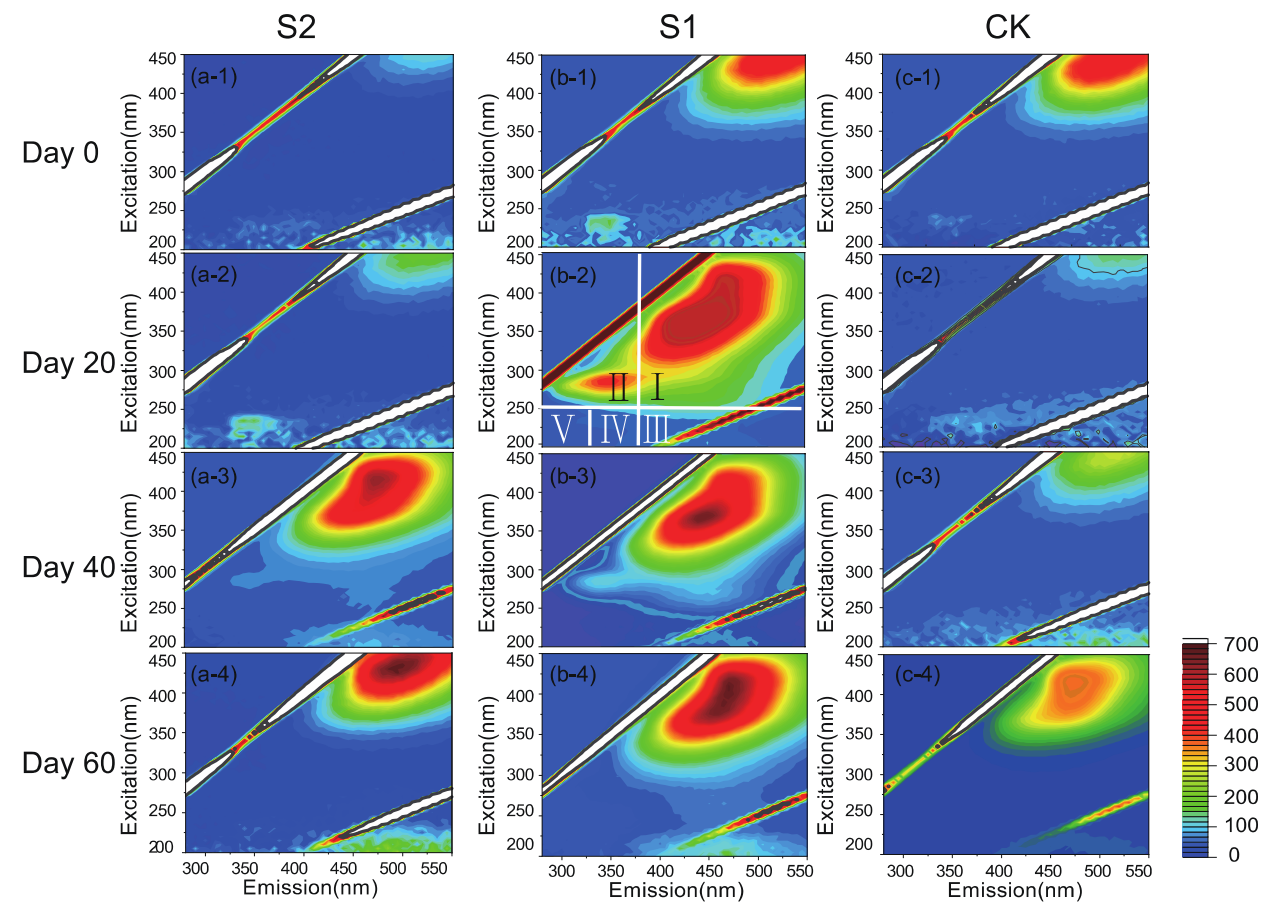

Figure 2. The EEM fluorescence spectra of DOM the during composting. Region I: humic acid-like substances. Region II: soluble microbial byproducts; Region III: fulvic acid-like substances; Regions IV and V: simple aromatic proteins (CK-no bedding material addition treatment; $\mathrm{S} 1-40 \%$ bedding material addition treatment; S2-25\% bedding material addition treatment).

The fluorescence of $\mathrm{OM}$ is influenced by condensed aromatic rings, unsaturated aliphatic carbon chains, or both [38]. The contours of DOM from the three composting treatments showed five peaks marked as I, II, III, IV and V (Figure 2). Peaks IV and V $(E m<380 \mathrm{~nm}, E x<250 \mathrm{~nm})$ in the early composting process represent aromatic proteins. Peak III $(E m>380 \mathrm{~nm}, \mathrm{Ex}<250 \mathrm{~nm})$, peak II $(\mathrm{Em}<380 \mathrm{~nm}, \mathrm{Ex}>250 \mathrm{~nm})$ and peak I $(\mathrm{Em}>380 \mathrm{~nm}, \mathrm{Ex}>250 \mathrm{~nm}$ ) are attributed to fulvic acid, water-soluble microbial metabolites, and humic acid, respectively. The fluorescence intensity of peak II decreased in S1 and 
S2 from the thermophilic stage, which was then followed by an increase. The fluorescence intensity of peaks IV and V showed a downward trend, and the fluorescence intensity of peaks I and III showed an upward trend. These results suggested that the primary reactions during the composting process were the transformation of protein and water-soluble microbial metabolites to fulvic acid and humic acid, especially during the mesophilic phase. The trend gradually shifted toward the stabilization of the newly formed humic and fulvic acid-like organic materials in the cooling and mature phases. The protein-like substance content and the humic and fulvic-like substance content ( $1>$ S2 $>$ CK) during composting supported our GI data because humic substances favored seed germination (Section 3.1). This result was an indicator of high DOM conversion efficiency during the composting process, which was likely due to the appropriate nutrient ratio and the fast rise in temperature during composting when $40 \%$ BM was added.

The reason that lignocellulose is difficult to biodegrade may be due to its special structural characteristics. For example, lignin is wrapped in the outer layer of the lignocellulose complex, and the cellulose and hemicellulose inside are not easily decomposed by microorganisms $[29,39]$. Table 3 shows that the degradation rate of cellulose in S1 was higher than the CK and S2 groups during composting $(p<0.05)$. This result most likely occurred because the scope of microbial activities expanded, and microorganism metabolism gradually increased during cellulose degradation [29]. On the 7th day, the degradation rate of cellulose in $\mathrm{S} 1$ showed the highest rate $(24.8 \%)$. The subsequent degradation rate of cellulose showed no significant difference between day 40 and day $60(p>0.05)$, which indicated that the cellulose degradation rate was stable in the cooling and mature phases. The degradation rate of hemicellulose in this experiment was always the highest relative to cellulose and lignin $(p<0.05)$, because hemicellulose is the most easily degradable organic substance in the process of composting via various microbiota and may provide basic substrates and materials for the growth and proliferation of microorganisms [40]. After day 20, a higher degradation rate of hemicellulose was observed in the S1 group compared to the CK and S2 groups $(p<0.05)$. Similarly to cellulose, there was no significant change in the degradation rate after day 20, which indicated that the rapid degradation of cellulose and hemicellulose occurred in the thermophilic stages. When the compost entered the final process, the S1 group maintained the highest degradation rate, of approximately $40 \%$, compared to the other treatments, which was 30\% for CK and 32.8\% for S2 $(p<0.05)$. During compost processing, the degradation rate of lignin first showed an increasing trend and subsequently entered a gradual downward trend (Table 3 ). During composting, the degradation rate of lignin in S1 always showed a higher rate compared to the CK group $(p<0.05)$. In contrast to cellulose and hemicellulose degradation, the lignin degradation rate on days 40 and 60 was higher than the other composting times $(p<0.05)$, which indicated that lignin degradation primarily occurred in late composting, which was likely because lignin is a complex organic polymer that is generally interconnected with cellulose and hemicellulose to form a lignocarbohydrate complex, which is resistant to biodegradation [41]. These data showed that $40 \%$ BM accelerated organic matter conversion and humification to a certain extent, which effectively improved the production of humus substances. It also played an important role in increasing the decomposition of lignocellulose.

\subsection{Similarity and Diversity of Microbial Communities}

A total of 31,081 bacterial sequences and 36,761 fungal sequences from all samples were analyzed after quality filtering. Venn diagrams showed that the unique OTU numbers in the S1 group were significantly higher than the $\mathrm{CK}$ and $\mathrm{S} 2$ groups $(p<0.05)$, and the unique fungal OTU numbers in S1 were higher than the CK and S2 groups $(p<0.05)$ (Figure S2). Venn diagram in the $\mathrm{S} 1$ group at different time points showed that only six common fungal OTUs were identified from fungal OTU libraries, belonging to the genera Pseudeurotium (OTU810), Mycothermus (OUT47, OTU417), and some other unclassified_k_Fungi, which indicated that $\mathrm{BM}$ changed the fungal community during composting. Table 4 presents the changes in microbial diversity and the richness of all the samples. The coverage indexes of 
all samples were greater than $99 \%$, which indicates that the sequencing results represent the actual state of each respective microbial community. Due to the higher temperatures, the indexes of bacterial diversity (Shannon and Simpson index) and richness (Chao1 and Ace index) initially decreased in the three groups entering the thermophilic stage (20 days), followed by an increasing trend in the cooling and mature phases. The fungal community diversity (Shannon and Simpson index) of the S1 group was lower than the CK and S2 groups $(p<0.05)$. During mesophilic and thermophilic phases, the Chao1 and Ace indexes of the bacterial and fungal communities significantly increased in the S1 group compared to the CK and S2 groups $(p<0.05)$. There was no significant difference between the Shannon and Simpson indexes of bacteria and fungi or the Chao1 and Ace indexes of bacteria and fungi $(p>0.05)$. The addition of BM increased the abundance of bacteria and fungi during the thermophilic period, and the decrease in diversity in fungi during the thermophilic period suggested dominant species during that period.

Table 4. Alpha diversity of bacterial and fungal communities during composting.

\begin{tabular}{ccccccc}
\hline Treatment & Time (Day) & Coverage & $\begin{array}{c}\text { Chao 1 } \\
\text { Bacteria/FungI }\end{array}$ & $\begin{array}{c}\text { Ace } \\
\text { Bacteria/FungI }\end{array}$ & $\begin{array}{c}\text { Shannon } \\
\text { Bacteria/FungI }\end{array}$ & $\begin{array}{c}\text { Simpson } \\
\text { Bacteria/FungI }\end{array}$ \\
\hline & & & \multicolumn{2}{c}{ Richness } & \multicolumn{2}{c}{ Diversity } \\
\hline & 0 & 1.0 & $773.72 / 226.29$ & $987.01 / 219.31$ & $4.11 / 3.43$ & $0.16 / 0.28$ \\
CK & 7 & 1.0 & $684.02 / 223.12$ & $718.87 / 221.05$ & $3.26 / 3.01$ & $0.12 / 0.23$ \\
& 20 & 1.0 & $294.23 / 104.09$ & $363.55 / 106.90$ & $2.47 / 2.84$ & $0.10 / 0.25$ \\
& 40 & 1.0 & $676.01 / 126.01$ & $456.99 / 122.36$ & $3.88 / 1.35$ & $0.11 / 0.18$ \\
& 60 & 1.0 & $799.19 / 131.27$ & $480.58 / 126.16$ & $4.82 / 2.43$ & $0.12 / 0.20$ \\
\hline \multirow{3}{*}{ S1 } & 0 & 1.0 & $985.68 / 303.29$ & $992.26 / 223.35$ & $4.19 / 4.21$ & $0.15 / 0.25$ \\
& 7 & 1.0 & $747.16 / 223.27$ & $656.44 / 216.22$ & $3.15 / 2.13$ & $0.09 / 0.23$ \\
& 20 & 1.0 & $656.23 / 184.37$ & $589.49 / 131.97$ & $2.13 / 2.04$ & $0.08 / 0.21$ \\
& 40 & 1.0 & $686.57 / 171.75$ & $695.05 / 170.35$ & $3.95 / 2.38$ & $0.25 / 0.25$ \\
& 60 & 1.0 & $652.07 / 135.38$ & $659.59 / 236.58$ & $3.88 / 2.33$ & $0.27 / 0.26$ \\
\hline \multirow{2}{*}{ S2 } & 1.0 & $949.29 / 313.05$ & $1097.23 / 283.97$ & $2.17 / 4.11$ & $0.23 / 0.31$ \\
& 7 & 1.0 & $750.12 / 203.14$ & $719.71 / 258.62$ & $3.12 / 3.69$ & $0.25 / 0.25$ \\
& 20 & 1.0 & $315.55 / 103.64$ & $411.23 / 112.69$ & $2.98 / 3.28$ & $0.11 / 0.28$ \\
& 40 & 1.0 & $580.02 / 128.05$ & $670.02 / 128.36$ & $2.84 / 3.85$ & $0.10 / 0.18$ \\
\hline
\end{tabular}

The number following CK/S1/S2 indicates sampling time (day). (CK-no bedding material addition treatment; S1-40\% bedding material addition treatment; S2-25\% bedding material addition treatment).

\subsection{Bacterial Community Succession and Predicted Bacterial Functions}

A closer observation of the bacterial phylum revealed five dominant groups in the three composting systems: Proteobacteria, Firmicutes, Chloroflexi, Bacteroidetes, and Actinobacteria (Figure 3a). The most common phylum among the three treatments was Firmicutes (47.3\%), which plays a major role in lignocellulose degradation [42]. Notably, the relative abundance (RA) of Firmicutes in S1 and S2 was higher than that in CK during composting $(p<0.05)$, which indicated that the addition of BW could promote the growth of Firmicutes in compost. It is consistent with previous work that different additives could promote Firmicutes in the compost $[19,42]$. The RA of Firmicutes showed the highest level in all treatments on day 20, which was $44.3 \%$ (CK), $65.8 \%$ (S1) and $62.7 \%$ (S2), respectively. This result indicated that Firmicutes survived well under high-temperature conditions and likely participate in the biodegradation of lignocellulose in the whole composting process [43]. The RA of Proteobacteria was higher in the early composting process and was considered a vital microbial component in the biodegradation of agricultural wastes [44]. During the thermophilic stages of composting, the relative abundance of Proteobacteria showed no obvious change in $\mathrm{CK}$, and decreasing trends were found in BM-supplemented composting. The RA of Chloroflexi and Actinobacteria showed increasing trends during the composting of the BM-supplemented groups. Chloroflexi includes many thermophilic cellulose-degrading bacteria [45]. The RA of Actinobacteria remained at approximately $12 \%$ in the BM treatments, and the RA of CK was in the range of $2.1-8.9 \%$, which demonstrated that it is likely that Actinobacteria actively participated in OM biodegradation 
activities. Similar studies have shown that Actinobacteria stimulated microbes to produce lignocellulosic hydrolases, which increased the OM decomposition [10,22]. Previous works confirmed that Actinobacteria secreted a variety of antibiotics to prevent the growth and proliferation of pathogenic microorganisms and increased the biodegradation of refractory substances [46].

(a)

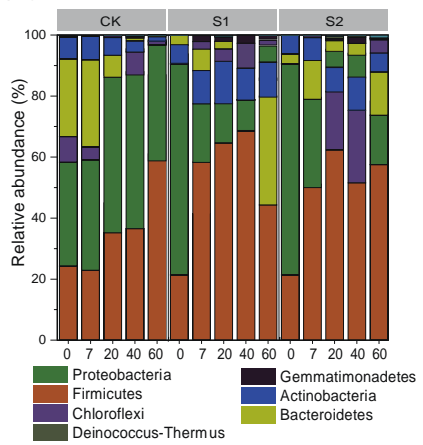

(b)

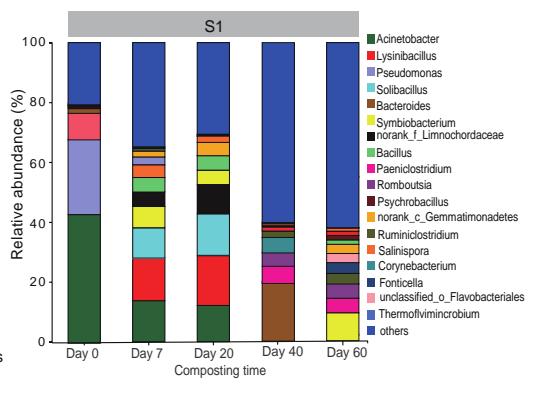

(c)

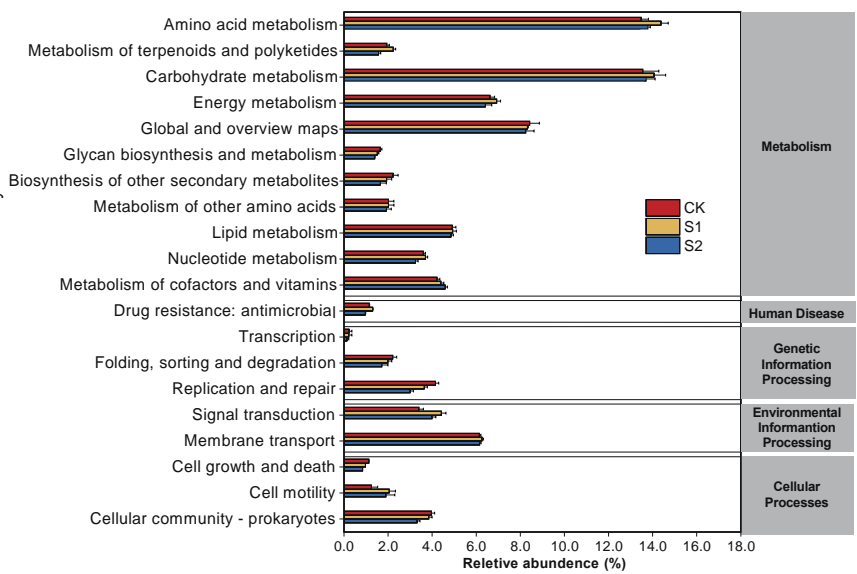

(d)

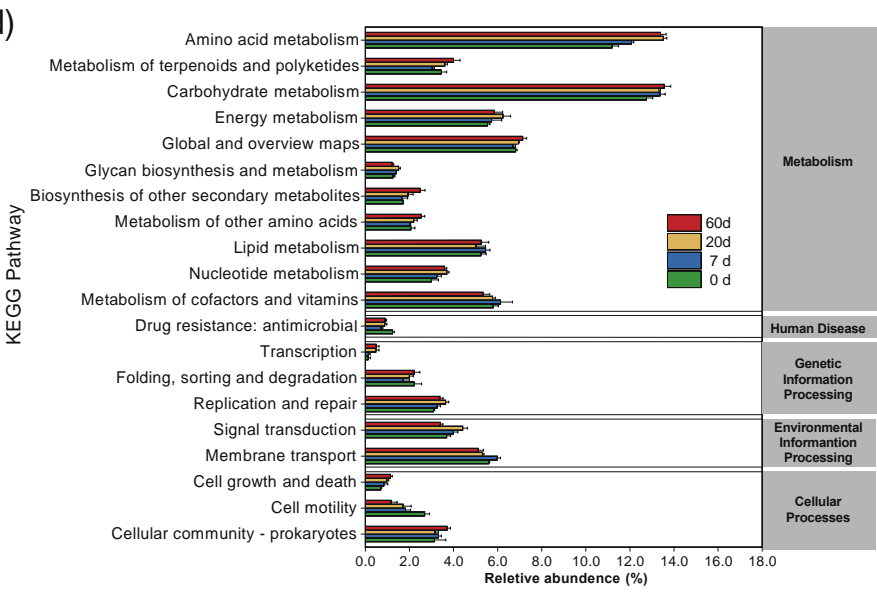

Figure 3. (a) Change in bacterial community composition in the three groups at the phylum level. (b) The relative abundance of fungal taxa at the genus level in S1. Taxa with $<1 \%$ of reads were combined as "others". The columns of different colors represent different species, and the length of the columns represents the proportion of the species. The metabolic function categories of bacterial communities analyzed by PICRUSt (c) in the different treatments, (d) at different time points during the $\mathrm{S} 1$ composting process. (CK-no bedding material addition treatment; S1-40\% bedding material addition treatment; S2-25\% bedding material addition treatment). 
Further observation of the bacterial genera showed the bacterial community dynamics during the composting process of S1 (Figure 3b). Acinetobacter (42.5\%), Pseudomonas (25.57\%), and Psychrobacillus (8.86\%) were the most abundant genera in the original compost mixture. Acinetobacter are ubiquitous in nature and exist in various environments, including sludge, sewage, and wastewater [47]. The strain belonging to genus Pseudomonas' (Pseudomonas aeruginosa in origin) compost is a relatively common and potential pathogen related to serious lung diseases, while Pseudomonas syringae and pathovars are the main pathogens related to plant spoilage in the natural environment [48]. After 7 days of composting, the pathogen genus Pseudomonas was not found in the late stages, probably reducing the risks to a certain extent. From day 7 to day 20, Lysinibacillus (13.97-16.61\%), Solibacillus (10.42-13.90\%), Acinetobacter (12.12-13.75\%), norank_f_Limnochordaceae (9.75-12.71\%), Bacillus (6.23-6.91\%) and Symbiobacterium (4.47-8.13\%) were the main genera (RA > 10\%). Except for Acinetobacter, most of the species identified are members of Firmicutes. At this stage, OM and lignocellulose were largely degraded, which indirectly demonstrated that Firmicutes were primarily responsible for the biodegradation of OM and acted as an indispensable OM-degrading phylum [43]. During this period of lignocellulose degradation, the most abundant genus, Lysinibacillus, possibly participated in the lignocellulose degradation. Similar results confirmed that Lysinibacillus was reported to be a celluloseand lignin-decomposing bacteria, with thermotolerant capacity, and may be used as a potential compost inoculant to accelerate the composting process [49-51]. Solibacillus may play an important role in the degradation of organic matter and lignocellulose, which was supported by a previous study [52]. Acinetobacter has the capacity for cellulase enzyme production and phenol biodegradation $[53,54]$. The relative abundances of Bacteroides $(19.09 \%)$ became the main genera in the cooling and mature stages.

The metabolic potential of bacterial communities was evaluated using PICRUSt according to the KEGG database. As predicted, there were three main functional categories, including metabolism, environment information processing, genetic information processing, cellular processes, and human diseases (Figure 3c,d). Amino acid metabolism (14.5\%), carbohydrate metabolism (13.7\%), energy metabolism (6.7\%), membrane transport (6.3\%), and lipid metabolism (4.8\%) showed significantly higher proportions in S1 compared to S2 and CK $(p<0.5)$ (Figure 3c). The RA of genes associated with carbohydrate metabolism, amino acid metabolism, and membrane transport remained high across all treatments, and this result likely occurred due to the biodegradation of nutrient-containing manure and $\mathrm{BM}$ wastes in the compost, such as crude proteinous complexes and sugars [29]. Amino acids, carbohydrates, lipids, and other substrates are generally available as nutritional substances and energy sources, which are conducive to the growth and reproduction of microorganisms, and increase the metabolism of microorganisms [20]. Figure $3 \mathrm{~d}$ shows that the metabolism group (49.87-52.76\%) was higher in S1 than the other treatment groups. The RA of genes associated with carbohydrate metabolism experienced an upward trend as composting proceeded. Notably, the slight decrease in the thermophilic stage was primarily due to the reduction in the amount of thermo-bacteria related to carbohydrate metabolism. Cellulose and hemicellulose were mostly contained in BMs during the mesophilic period, and a few dominant thermostable bacteria began to slowly degrade the difficult-to-degrade substances during the thermophilic period, during which there was a large reduction in mesophilic bacteria. The RA of genes related to terpenoid and polyketone metabolism increased rapidly after 7 days, which demonstrated the continuous decomposition of refractory substances. The RA related to the transportation and metabolism of amino acids increased in S1 during 7 days of composting and gradually stabilized after 20 days. A previous study proposed that a higher enrichment of amino acid metabolism increased bacterial types and the generation of more humic substances [55]. There was a decrease in the RA of genes associated with human disease during composting, which indicated that the $\mathrm{S} 1$ composting product became safer after day 0 . 


\subsection{Fungal Community Succession and Predicted Fungal Functions}

For the fungal community, six main phyla were detected during composting (Figure 4a): Ascomycota, Basidiomycota, Cercozoza, Neocallimastigomycota, Mortierellomycota and unclassified_k_Fungi. Ascomycota dominated the fungi in the three groups. Especially at the thermophilic phase of the S1 groups, Acomycota accounted for the greatest proportion of the classified OTUs, with an abundance of $90.7 \%$. The RA of Ascomycota showed an increasing trend as the temperate increased, then showed a downward trend. Entering the cooling stage, it remained stable until the composting was complete. This result may have occurred because Ascomycota utilize various energy sources and adapt well to extreme conditions, such as high-temperature stress and nutritional deficiency [56]. Similar trends were obtained previously [57]. Ascomycota played a vital role in lignocellulose-degrading consortium during cow manure compost with wood chips, and it may compete with endogenous fungi in metabolic activities for nutrients. Notably, the RA of Basidiomycota increased during S1 composting, which was different from the decreasing trend in S2. Ascomycota and Basidiomycota are the prominent phyla responsible for lignocellulose biodegradation, and a high proportion of these phyla accelerate the decomposition of organic complexes [58].

(a)

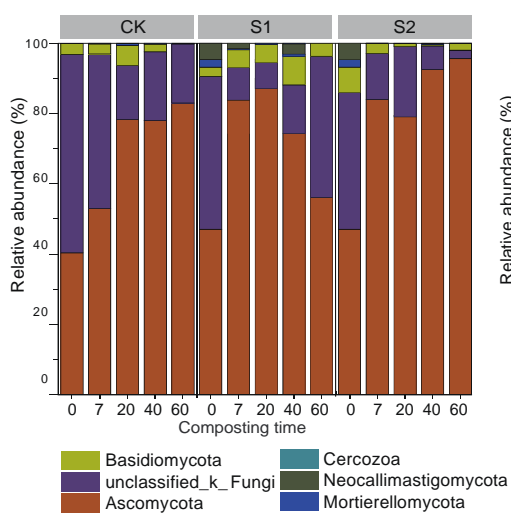

(b)

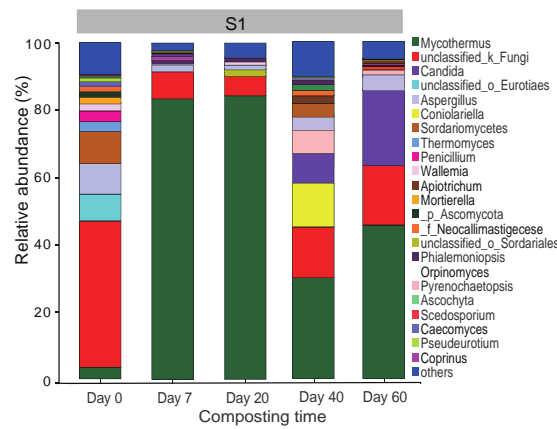

(c)

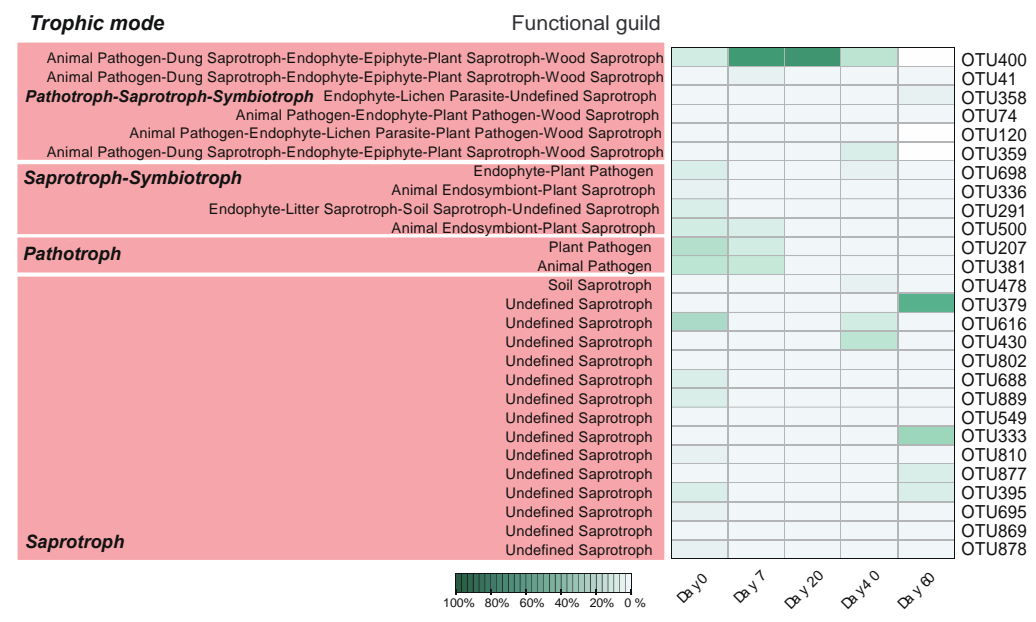

Figure 4. (a) Changes in fungal community composition at the phylum level in the three groups; (b) Change in fungal community composition in S1 at the genus level. The columns of different colors represent different species, and the length of the columns represents the proportion of the species. Taxa with $<1 \%$ of reads were combined as "others". (c) Fungal community trophic mode and functional guild based on FUNGuild. Top 30 OTUs are shown in the heatmap. (CK-no bedding material addition treatment; $\mathrm{S} 1-40 \%$ bedding material addition treatment; $\mathrm{S} 2-25 \%$ bedding material addition treatment). 
Figure $4 \mathrm{~b}$ shows the fungal genus composition in the S1 treatment, and the RA of the 20 most abundant classified fungal genera showed obvious variations over the composting period. Orpinomyces, which was detected only in the original CK, includes anaerobic fungi that are generally located in the gastrointestinal tract of animals, and seldom grow and reproduce in an aerobic composting environment [59]. Orpinomyces disappeared when composting started due to the generation of an aerobic environment. The thermophilic genus Mycothermus was dominant in the composting process, especially in the thermophilic phase $(85.7 \%)$. At this stage, the degradation rate of OM and lignocellulose was maintained at high levels, possibly indicating that the dominant strain Mycothermus played an absolute role on the degradation of OM and lignocellulose. Similarly to several studies, Mycothermus can produce thermostable cellulases, hemicellulases, and xylanase, and the microbial cluster with high temperature resistance, including the thermophilic strain $M y$ cothermus thermophilus and the series of Proteobacteria and Actinobacteria, was primarily responsible for the degradation of feedstock and the release of ammonia [60,61]. Candida and Aspergillus were found during all the composting stages, which shows their high adaptability to diverse environmental conditions (e.g., temperature, moisture, and $\mathrm{pH}$ ). Several Aspergillus fungal species produce different enzymes to decompose lignocellulose [62]. The thermophilic fungal genus exhibited a considerable capacity for complex polymer degradation. Mycothermus and Aspergillus dominated the fungal community at the thermophilic phase of composting, and they positively correlated with the carbon and nitrogen transformation parameters [62]. The relative abundance of Candida reached the highest value during the cooling and mature phases, and degraded various components of lignocelluloses, improved the transformation of precursor substances, and promoted the synthesis of humic substances [52]. Coniolariella, Pyrenochaetopsis, and Sordariomycetes were also the main genera in the cooling and mature phases.

The fungi in the composting of the S1 group, including the 30 most abundant OTUs, were classified by the ecological guild and trophic mode (Figure 4c). A neighbor-joining phylogenetic tree was constructed to demonstrate the phylogenetic relationships among the main fungal communities in the S1 treatment (Figure S3). Fungal trophic modes and guilds primarily included pathotrophs (plant and animal pathogen, 20.3\%), symbiotrophssaprotrophs (animal pathogen-plant pathogen-undefined saprotroph, 23.6\%), pathotrophssaprotrophs-symbiotrophs (animal pathogen-endophyte plant pathogen-wood saprotrophs, 16.3\%), and saprotrophs (undefined saprotrophs, 30.4\%) in the composting. Fungal trophic modes and guilds showed significant variation during anaerobic fermentation. Saprotrophs and pathotrophs were the predominant fungal trophic modes during the composting process, and saprotrophic fungi were the most common taxonomic group, with 13 OTUs classified into 11 known genera of Ascomycota (e.g., Aspergillus and Candida) and Basidiomycota (e.g., Wallemia) (Figure S3). Animal and plant pathogens existed in early compost, including Ascochyta (OTU 207) and Cutaneotrichosporon (OTU 381), and vanished after S1 composting, which indicated that the addition of $40 \%$ BM improved the safety of raw materials as an agricultural fertilizer. High temperature was the most critical environmental factor to effectively remove pathogens during aerobic composting [18]. Notably, the relative abundances of the OTUs of pathotrophs-saprotrophs-symbiotrophs (including wood saprotroph) started at only $16.3 \%$ on day 0 but increased quickly and became the dominant fungal group $(89.1 \%)$ in the thermophilic stage and almost disappeared in the mature stage. Similar trends of first quickly increasing then slightly decreasing were found in the changes in cellulose, hemicellulose, and lignin in Section 3.2. This result confirmed the efficient conversion of cellulose and hemicellulose during S1 composting. At the end of composting, saprotrophs became the main trophic mode, and the main saprotrophic fungi include Mycothermus, Aspergillus, Sordariomycetes, Candia, Coniolariella and Pyrenochaetopsis (Figure 4c and Figure S3). The core functional genera Mycothermus, Penicillium, and Aspergillus produce lignocellulose-degrading enzymes during composting [60]. Specifically, Mycothermus also acts as a key organism in the decomposition of plant materials and plant-derived compounds [63]. The thermophilic microbe Aspergillus has a high capacity 
to degrade lignocelluloses and lignin and uses foul-smelling sulfur-containing substances to prevent the diffusion of gaseous pollutants during composting [52,64]. Several studies found that the saprotrophic fungus Sordariomycetes accelerated the circulation and absorption of nutrients and the degradation of litter waste (fallen leaves and dung, etc.) [65].

\subsection{Co-Occurrence Network Analysis for Correlations in Microbial Community}

Microorganisms generally form complex networks via positive and negative interactions rather than living in isolation. To better understand the interaction between the microbial communities in BM addition composting, we constructed co-occurrence networks based on the relationship of the dominant bacterial and fungal genera (Figure 5). The BM affected co-occurrence networks between bacterial and fungal taxa and topological properties. The topological characteristics of the network in the S1 group were more complex than the other groups. The average weighted degree 5.550 in S1 was higher than 3.447 in CK and 4.130 in S2. Compared to the CK and S2 groups, the number of nodes increased by $12.0 \%$ and $14.5 \%$, and the number of edges increased by $35.2 \%$ and $19.7 \%$, respectively. The network diameter in the S1 treatment also increased by $30 \%$ and $40 \%$, respectively, compared with $\mathrm{CK}$ and $\mathrm{S} 2$. The above results showed that there were closer interactions among microbial communities in the S1 treatment than in the CK and S2 treatments. Symbiobacterium, Thermobispora, Thermopolyspora, and Thermoflavimicrobium, etc., had positively correlated with each other in S1 $(p<0.05)$. The most abundant fungal genus, Mycothermus, in the S1 composting had many correlations with other genera. Notably, the bacterial genus Bacteroides, which was the dominant genus in the cooling and mature phase in $\mathrm{S} 1$ composting, was negatively related to various bacteria and fungi, such as Solibacillus, Lysinibaccilus, Micothermus, Penicillum, and Coniolariella $(p<0.05)$. There were more positive correlations with each other in the BM addition groups than the control group (Figure 5).

\subsection{Relationships of the Bacterial/Fungal Community with Physicochemical Characteristics}

CCA, RDA and Spearman correlation heatmaps were used to describe the relationships between the microbial community and physicochemical properties (temperature, $\mathrm{OM}, \mathrm{C} / \mathrm{N}$, and lignocellulose, etc.) in the different compost processes (Figure 6). The CCA results demonstrated that the correlation between environmental factors and the bacterial community was $\mathrm{OM}>$ hemicellulose $>\mathrm{C} / \mathrm{N}>$ moisture $>$ cellulose $>$ temperature $>$ lignin $>\mathrm{pH}$ (Figure 6a). The microbial samples on day 0 were more affected by $\mathrm{OM}$ and water content. Entering the mesophilic and thermophilic stages, especially in the S1 system, temperature was the main environmental factor. Figure $6 \mathrm{c}$ shows the relationship between the dominant bacterial genera and physicochemical properties. Lysinibacillus and Symbiobacterium had a positive relationship with cellulose, lignin, and hemicellulose $(p<0.01)$, and negatively related to $\mathrm{C} / \mathrm{N}(p<0.01)$, which indicated Lysinibacillus and Symbiobacterium possibly participated in the lignocellulose degradation. Corynebacterium was negatively related to cellulose and hemicellulose $(p<0.001)$ but positively related to OM and C/N $(p<0.01)$. Sphaerobater and Solibacillus were positively related to temperature $(p<0.01)$, and Pseudomonas was negatively related to temperature $(p<0.01)$, which demonstrated a close relationship between bacterial communities and physicochemicals. $\mathrm{C} / \mathrm{N}$ and $\mathrm{OM}$ had positive associations with Psychrobacter and Sporosarcina but negative associations with Bacillus and Solibacillus $(p<0.05)$.

Figure $6 \mathrm{~b}$ shows that the relationship between physicochemical properties and the fungal genera was as follows: $\mathrm{OM}>\mathrm{C} / \mathrm{N}>$ hemicellulose $>$ moisture $>$ cellulose $>$ lignin $>\mathrm{pH}$ $>$ temperature. Compared to bacteria, temperature had a lower effect on fungi. Similarly to the bacterial community, hemicellulose positively correlated with cellulose, temperature, $\mathrm{pH}$, and lignin content and was negatively related to $\mathrm{OM}$ and $\mathrm{C} / \mathrm{N}$. The fungal samples on day 0 were more affected by water content. In contrast to bacteria, cellulose, hemicellulose, and lignin were the main environmental factors during the mesophilic and thermophilic stages. OM became the dominant environmental property and strongly correlated with the fungal community at the end of composting. Figure 6d shows that Aspergillus, Candida, 
and Sordariomycetes were positively related to cellulose and hemicellulose $(p<0.01)$ but negatively related to OM and $\mathrm{C} / \mathrm{N}(p<0.05)$. In addition, the most abundant taxa $M y-$ cothermus in S1, which was positively correlated to cellulose and negatively correlated to $\mathrm{C} / \mathrm{N}(p<0.05)$, indirectly confirmed the result in the Section 3.6 that Mycothermus could act as a key organism in the efficient degradation of cellulose and hemicellulose. Ascochyta was negatively related to cellulose and hemicellulose $(p<0.01)$, while it was positively correlated to OM and $\mathrm{C} / \mathrm{N}(p<0.05)$. Cellulose, hemicellulose, and lignin were also negatively related to Talaromyces, Wallemia and Microascus, while they were positively related to Penicillium $(p<0.05)$. These results showed that cellulose, hemicellulose, and OM had strong associations with the succession of bacteria and fungi, and $\mathrm{C} / \mathrm{N}$ and lignin jointly affected the microbial community. Temperature had a lower influence on the dynamics of fungi than bacteria.

(a)

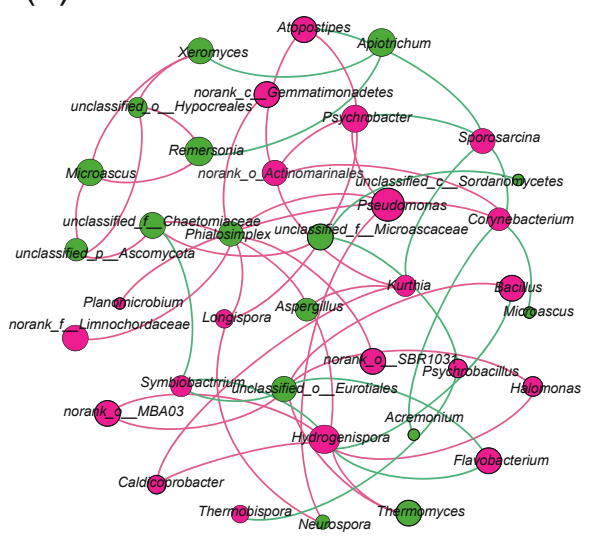

Bacteria

Fungi

(c)

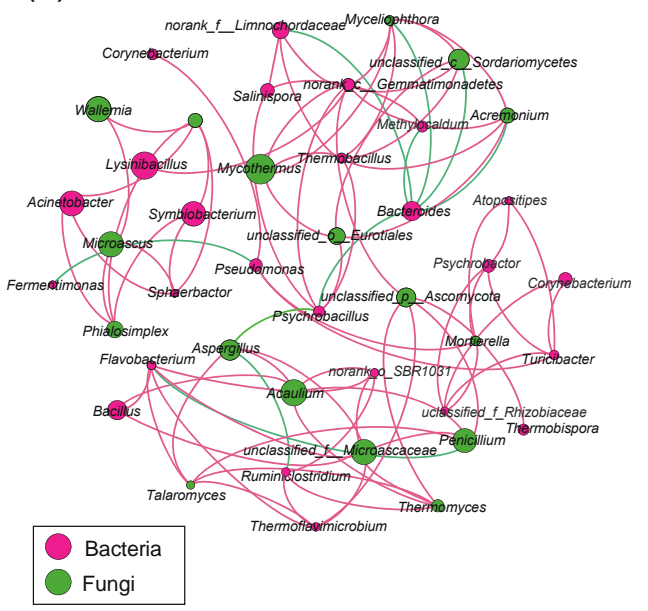

(b)

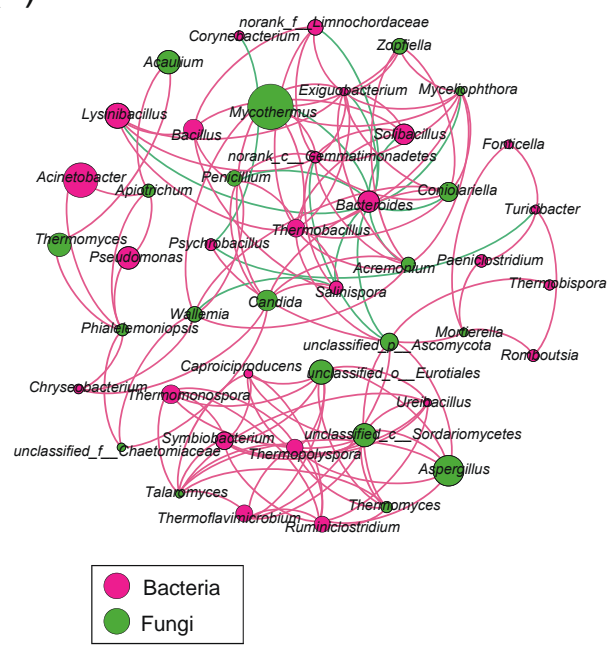

(d)

\begin{tabular}{cccc}
\hline Parameter & CK & S1 & S2 \\
\hline Edge & 79 & 122 & 98 \\
Node & 36 & 48 & 41 \\
Average Degree & 3.447 & 5.550 & 4.130 \\
Network Diameter & 7 & 10 & 6 \\
\hline
\end{tabular}

Figure 5. Network analysis showing the co-occurrence based on the correlation among dominant taxa. The control group (a); the S1 group (b); the S2 group (c); (d). The topological parameters of networks. Red edges: Positive correlation; green edges: Negative correlation; the size of nodes indicates the average relative abundance of the genera. (CK-no bedding material addition treatment; S1- $40 \%$ bedding material addition treatment; S2-25\% bedding material addition treatment). 
(a)

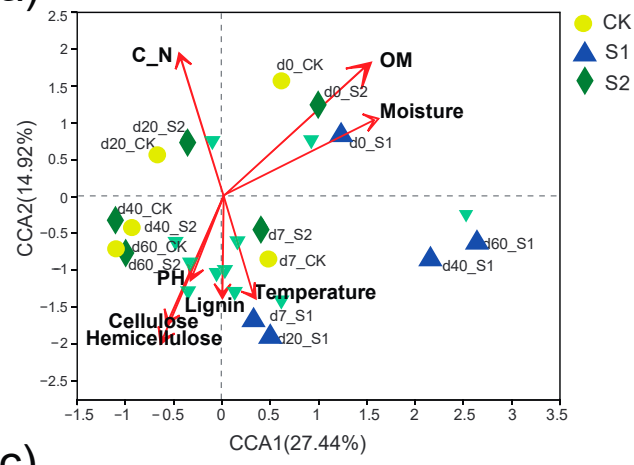

(c)

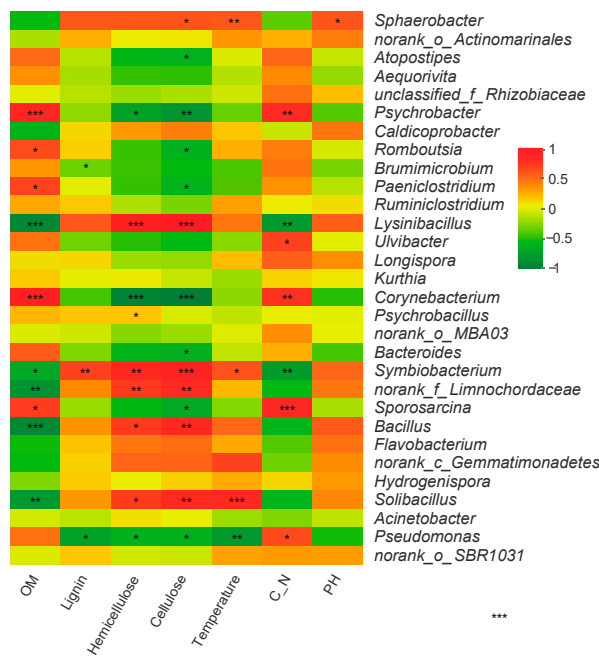

(b)

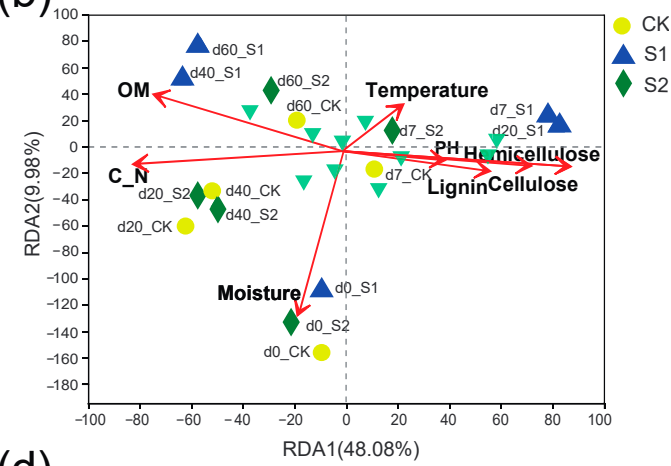

(d)

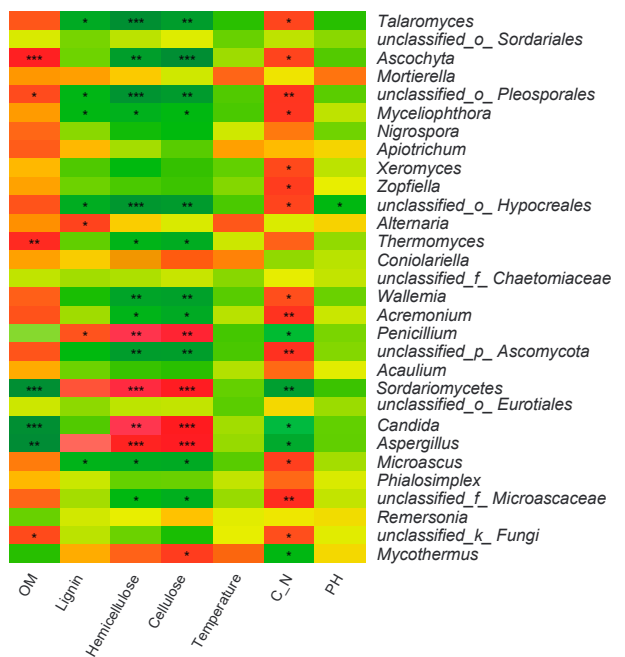

Figure 6. (a) Canonical correspondence analysis (CCA) of the relationship between physicochemical properties and bacterial genera. (b) Redundancy analysis (RDA) of the relationship between environmental parameters and fungal genera. Correlation analysis of physicochemical properties and the top 30 (c) bacterial genera and (d) fungal genera. $\left({ }^{*} 0.01<p \leq 0.05,{ }^{* *} 0.001<p \leq 0.01,{ }^{* * *} p \leq 0.001\right.$ ) (CK-no bedding material addition treatment; S1-40\% bedding material addition treatment; S2-25\% bedding material addition treatment).

\section{Conclusions}

This work designed a composting system in which cow manure and bedding material waste (BM) waste were used as feedstock to simultaneously handle two agricultural wastes. The $40 \%$ BM significantly improved the duration of high temperatures $\left(>55^{\circ} \mathrm{C}, 25\right.$ days) and increased the GI value (51.3\%) and OM degradation (10.4\%) $(p<0.05)$ during composting. Firmicutes was more abundant in S1 and S2, but Proteobacteria was more abundant in CK. Cellulose, hemicellulose, and OM had strong associations with bacteria and fungi, such as Lysinibacillus and Corynebacterium (bacteria) and Aspergillus, Candida, and Sordariomycetes (fungi). Mycothermus acted as a key organism in the efficient degradation of cellulose and hemicellulose. Network analysis indicated the closer interactions of the microbial community in the S1 group than in the other groups. This study showed instructive significance for improving the efficiency and quality of compost, using bedding material waste as a compost amendment. These findings also provide detailed information about how the dynamic changes in bacteria and fungi in the composting process are closely related to material conversion.

Supplementary Materials: The following are available online at https:/ /www.mdpi.com/article/10.3 390/su132313035/s1, Figure S1: Profiles of (a) OM, the degradation rate of (b) cellulose, (c) hemicellulose, (d) lignin, Figure S2: Similarity analysis of bacterial and fungal communities in the different composts. Venndiagram of (a) bacterial OTUs of three groups; (b) fungal OTUs of three groups; (c) bacterial OTUs 
in S1 at the different timepoints; (d) fungal OTUs in S1 at the different timepoints., Figure S3: Phylogram of the top 30 fungal species in $\mathrm{S} 1$ compost.

Author Contributions: Conceptualization, J.S. (Junsong Sun), B.Z. and H.D.; methodology, H.D.; software, H.D.; validation, H.D., J.S. (Junsong Sun) and B.Z.; formal analysis, H.D., M.J. and Y.X.; investigation, M.J., J.S. (Jiping Shi) and Y.X.; resources, J.S. (Jiping Shi) and J.S. (Junsong Sun); data curation, H.D.; writing-original draft preparation, H.D.; writing—review and editing, J.S. (Junsong Sun) and B.Z.; visualization, J.S. (Junsong Sun); supervision, J.S. (Junsong Sun) and B.Z.; project administration, J.S. (Junsong Sun) and L.L.; funding acquisition, J.S. (Junsong Sun), L.L. and J.S. (Jiping Shi). All authors have read and agreed to the published version of the manuscript.

Funding: This research was funded by the National Key Research and Development Program of China (2018YFC1901000), the Science and Technology Service Network Initiative Project of the Chinese Academy of Sciences (KFJ-STS-QYZX-112) and the Shanghai Engineering Research Center of Biotransformation of Organic Solid Waste Program (SERC2021C03).

Institutional Review Board Statement: Not applicable.

Informed Consent Statement: Not applicable.

Data Availability Statement: The datasets generated for this study can be found in Sequence Read Archive under BioProject, BioProject ID: PRJNA694866 (https:/ / www.ncbi.nlm.nih.gov/sra/, accessed on 26 October 2021).

Acknowledgments: We thank Ji Xiang Farm for their contributions to sample collection.

Conflicts of Interest: The authors declare no conflict of interest, and the funder had no role in the design of the study, in the collection, analyses, or interpretation of data, in the writing of the manuscript; or in the decision to publish the results.

\section{References}

1. World Health Organization. WHO Report on the Global Tobacco Epidemic, 2017: Monitoring Tobacco Use and Prevention Policies; World Health Organization: Geneva, Switzerland, 2017.

2. Wang, K.; Chu, C.; Li, X.; Wang, W.; Ren, N. Succession of Bacterial Community Function in Cow Manure Composing. Bioresour. Technol. 2018, 267, 63-70. [CrossRef] [PubMed]

3. Safferman, S.I.; Wallace, J.M. Cow Manure: Waste Or Resource? IEEE Potentials 2015, 34, 25-29. [CrossRef]

4. Wang, Y.; Gong, J.; Li, J.; Xin, Y.; Hao, Z.; Chen, C.; Li, H.; Wang, B.; Ding, M.; Li, W.; et al. Insights into Bacterial Diversity in Compost: Core Microbiome and Prevalence of Potential Pathogenic Bacteria. Sci. Total Environ. 2020, 718, 137304. [CrossRef]

5. Husfeldt, A.W.; Endres, M.I.; Salfer, J.A.; Janni, K.A. Management and Characteristics of Recycled Manure Solids Used for Bedding in Midwest Freestall Dairy Herds. J. Dairy Sci. 2012, 95, 2195-2203. [CrossRef] [PubMed]

6. Fournel, S.; Godbout, S.; Ruel, P.; Fortin, A.; Duquette-Lozeau, K.; Létourneau, V.; Généreux, M.; Lemieux, J.; Potvin, D.; Côté, C.; et al. Production of Recycled Manure Solids for Use as Bedding in Canadian Dairy Farms: II. Composting Methods. J. Dairy Sci. 2019, 102, 1847-1865. [CrossRef]

7. Leso, L.; Barbari, M.; Lopes, M.A.; Damasceno, F.A.; Galama, P.; Taraba, J.L.; Kuipers, A. Invited Review: Compost-Bedded Pack Barns for Dairy Cows. J. Dairy Sci. 2020, 103, 1072-1099. [CrossRef]

8. Atencio, J.L.; Fernandez, J.A.; Gernat, A.G.; Murillo, J.G. Effect of Pine Wood Shavings, Rice Hulls and River Bed Sand on Broiler Productivity When Used as a Litter Sources. Int. J. Poult. Sci. 2010, 9, 240-243. [CrossRef]

9. Wolfe, T.; Vasseur, E.; Devries, T.J.; Bergeron, R. Effects of Alternative Deep Bedding Options on Dairy Cow Preference, Lying Behavior, Cleanliness, and Teat End Contamination. J. Dairy Sci. 2018, 101, 530-536. [CrossRef]

10. Awasthi, M.K.; Chen, H.; Wang, Q.; Liu, T.; Duan, Y.; Awasthi, S.K.; Ren, X.; Tu, Z.; Li, J.; Zhao, J.; et al. Succession of Bacteria Diversity in the Poultry Manure Composted Mixed with Clay: Studies upon Its Dynamics and Associations with Physicochemical and Gaseous Parameters. Bioresour. Technol. 2018, 267, 618-625. [CrossRef] [PubMed]

11. Guo, R.; Li, G.; Jiang, T.; Schuchardt, F.; Chen, T.; Zhao, Y.; Shen, Y. Effect Of Aeration Rate, C/N Ratio And Moisture Content On The Stability And Maturity Of Compost. Bioresour. Technol. 2012, 112, 171-178. [CrossRef]

12. He, X.S.; Xi, B.D.; Wei, Z.M.; Jiang, Y.H.; Geng, C.M.; Yang, Y.; Yuan, Y.; Liu, H.L. Physicochemical and Spectroscopic Characteristics of Dissolved Organic Matter Extracted from Municipal Solid Waste (MSW) and Their Influence on the Landfill Biological Stability. Bioresour. Technol. 2011, 102, 2322-2327. [CrossRef]

13. Esmaeili, A.; Khoram, M.R.; Gholami, M.; Eslami, H. Pistachio Waste Management Using Combined CompostingVermicomposting Technique: Physico-Chemical Changes and Worm Growth Analysis. J. Clean Prod. 2020, $242,118523$. [CrossRef]

14. Guo, A.; Zhao, Z.; Zhang, P.; Yang, Q.; Li, Y.; Wang, G. Linkage between Soil Nutrient and Microbial Characteristic in an Opencast Mine, China. Sci. Total Environ. 2019, 671, 905-913. [CrossRef] [PubMed] 
15. Jeong, K.H.; Kim, J.K.; Ravindran, B.; Lee, D.J.; Wong, J.W.; Selvam, A.; Karthikeyan, O.P.; Kwag, J.H. Evaluation of Pilot-Scale in-Vessel Composting for Hanwoo Manure Management. Bioresour. Technol. 2017, 245, 201-206. [CrossRef]

16. Ren, L.; Schuchardt, F.; Shen, Y.; Li, G.; Li, C. Impact of Struvite Crystallization on Nitrogen Losses during Composting of Pig Manure and Cornstalk. Waste Manag. 2010, 30, 885-892. [CrossRef] [PubMed]

17. Kebibeche, H.; Khelil, O.; Kacem, M.; Kaid Harche, M. Addition of Wood Sawdust during the Co-Composting of Sewage Sludge and Wheat Straw Influences Seeds Germination. Ecotoxicol. Environ. Saf. 2019, 168, 423-430. [CrossRef] [PubMed]

18. Duan, Y.; Awasthi, S.K.; Liu, T.; Chen, H.; Zhang, Z.; Wang, Q.; Ren, X.; Tu, Z.; Awasthi, M.K.; Taherzadeh, M.J. Dynamics of Fungal Diversity and Interactions with Environmental Elements in Response to Wheat Straw Biochar Amended Poultry Manure Composting. Bioresour. Technol. 2019, 274, 410-417. [CrossRef] [PubMed]

19. Meng, Q.; Yang, W.; Men, M.; Bello, A.; Xu, X.; Xu, B.; Deng, L.; Jiang, X.; Sheng, S.; Wu, X.; et al. Microbial Community Succession and Response to Environmental Variables During Cow Manure and Corn Straw Composting. Front. Microbiol. $2019,10,529$. [CrossRef]

20. Lopez-Gonzalez, J.A.; Suarez-Estrella, F.; Vargas-Garcia, M.C.; Lopez, M.J.; Jurado, M.M.; Moreno, J. Dynamics Of Bacterial Microbiota during Lignocellulosic Waste Composting: Studies upon Its Structure, Functionality and Biodiversity. Bioresour. Technol. 2015, 175, 406-416. [CrossRef]

21. Hosseini, S.M.; Aziz, H.A. Evaluation of Thermochemical Pretreatment and Continuous Thermophilic Condition in Rice Straw Composting Process Enhancement. Bioresour. Technol. 2013, 133, 240-247. [CrossRef]

22. Taha, M.; Foda, M.; Shahsavari, E.; Aburto-Medina, A.; Adetutu, E.; Ball, A. Commercial Feasibility of Lignocellulose Biodegradation: Possibilities and Challenges. Curr. Opin. Biotechnol. 2016, 38, 190-38197. [CrossRef]

23. Jain, M.S.; Daga, M.; Kalamdhad, A.S. Physical Parameters Evaluation during Production of Soil Conditioner from Aquatic Waste: Hydrilla Verticillata (L.F.) Royle. Environ. Technol. Innov. 2018, 11, 64-73. [CrossRef]

24. Zhang, L.; Sun, X. Addition of Fish Pond Sediment and Rock Phosphate Enhances the Composting of Green Waste. Bioresour. Technol. 2017, 233, 116-126. [CrossRef] [PubMed]

25. Van Soest, P.J.; Robertson, J.B.; Lewis, B.A. Methods for Dietary Fiber, Neutral Detergent Fiber, and Nonstarch Polysaccharides in Relation to Animal Nutrition. J. Dairy Sci. 1991, 74, 3583-3597. [CrossRef]

26. Holman, D.B.; Hao, X.; Topp, E.; Yang, H.E.; Alexander, T.W. Effect of Co-Composting Cattle Manure with Construction and Demolition Waste on the Archaeal, Bacterial, and Fungal Microbiota, and on Antimicrobial Resistance Determinants. PLoS ONE 2016, 11, E0157539.

27. Nguyen, N.H.; Song, Z.; Bates, S.T.; Branco, S.; Tedersoo, L.; Menke, J.; Schilling, J.S.; Kennedy, P.G. Funguild: An Open Annotation Tool for Parsing Fungal Community Datasets by Ecological Guild. Fungal Ecol. 2016, 20, 241-248. [CrossRef]

28. Du, G.; Feng, W.; Cai, H.; Ma, Z.; Liu, X.; Yuan, C.; Shi, J.; Zhang, B. Exogenous Enzyme Amendment Accelerates Maturity and Changes Microflora Succession in Horse and Wildlife Animal Manure Co-Composting. Environ. Sci. Pollut. Res. 2021, 28, 21610-21620. [CrossRef]

29. Wu, D.; Wei, Z.; Zhao, Y.; Zhao, X.; Mohamed, T.A.; Zhu, L.; Wu, J.; Meng, Q.; Yao, C.; Zhao, R. Improved Lignocellulose Degradation Efficiency Based on Fenton Pretreatment during Rice Straw Composting. Bioresour. Technol. 2019, $294,122132$. [CrossRef]

30. Zhou, H.; Zhao, Y.; Yang, H.; Zhu, L.; Cai, B.; Luo, S.; Cao, J.; Wei, Z. Transformation of Organic Nitrogen Fractions with Different Molecular Weights during Different Organic Wastes Composting. Bioresour. Technol. 2018, 262, 221-228. [CrossRef] [PubMed]

31. Reyes-Torres, M.; Oviedo-Ocana, E.R.; Dominguez, I.; Komilis, D.; Sanchez, A. A Systematic Review on the Composting of Green Waste: Feedstock Quality and Optimization Strategies. Waste Manag. 2018, 77, 486-499. [CrossRef] [PubMed]

32. Zhang, D.; Luo, W.; Li, Y.; Wang, G.; Li, G. Performance of Co-Composting Sewage Sludge and Organic Fraction of Municipal Solid Waste at Different Proportions. Bioresour. Technol. 2018, 250, 853-859. [CrossRef] [PubMed]

33. Gou, C.; Wang, Y.; Zhang, X.; Lou, Y.; Gao, Y. Inoculation with a Psychrotrophic-Thermophilic Complex Microbial Agent Accelerates Onset and Promotes Maturity of Dairy Manure-Rice Straw Composting under Cold Climate Conditions. Bioresour. Technol. 2018, 243, 339-346. [CrossRef]

34. Nakasaki, K.; Araya, S.; Mimoto, H. Inoculation of Pichia Kudriavzevii RB1 Degrades the Organic Acids Present in Raw Compost Material and Accelerates Composting. Bioresour. Technol. 2013, 144, 521-528. [CrossRef] [PubMed]

35. Zhan, Y.; Wei, Y.; Zhang, Z.; Zhang, A.K.; Li, Y.; Li, J. Effects of Different C/N Ratios on the Maturity and Microbial Quantity of Composting with Sesame Meal and Rice Straw Biochar. Biochar 2021, 3, 557-564. [CrossRef]

36. Awasthi, M.K.; Pandey, A.K.; Khan, J.; Bundela, P.S.; Wong, J.W.; Selvam, A. Evaluation of Thermophilic Fungal Consortium for Organic Municipal Solid Waste Composting. Bioresour. Technol. 2014, 168, 214-221. [CrossRef] [PubMed]

37. Shi, J.-G.; Zeng, G.-M.; Yuan, X.-Z.; Dai, F.; Liu, J.; Wu, X.-H. The Stimulatory Effects of Surfactants on Composting of Waste Rich in Cellulose. World J. Microbiol. Biotechnol. 2006, 22, 1121-1127. [CrossRef]

38. Lv, B.; Xing, M.; Yang, J.; Qi, W.; Lu, Y. Chemical and Spectroscopic Characterization of Water Extractable Organic Matter during Vermicomposting of Cattle Dung. Bioresour. Technol. 2013, 132, 320-326. [CrossRef]

39. Rajput, A.A.; Zeshan, C. Visvanathan. Effect of Thermal Pretreatment on Chemical Composition, Physical Structure and Biogas Production Kinetics of Wheat Straw. J. Environ.Manag. 2018, 221, 45-52. [CrossRef] [PubMed]

40. Paradelo, R.; Moldes, A.B.; Barral, M.T. Evolution of Organic Matter during the Mesophilic Composting of Lignocellulosic Winery Wastes. J. Environ. Manag. 2013, 116, 18-26. [CrossRef] 
41. Glasser, W.G. About Making Lignin Great Again-Some Lessons from the Past. Front. Chem. 2019, 7, 565. [CrossRef]

42. Li, J.; Xing, W.; Bao, H.; Wang, J.; Tong, X.; Zhang, H.; Luo, W.; Wu, F. Impact of Pine Leaf Biochar Amendment on Bacterial Dynamics and Correlation of Environmental Factors during Pig Manure Composting. Bioresour. Technol. 2019, $293,122031$. [CrossRef]

43. Awasthi, M.K.; Duan, Y.; Awasthi, S.K.; Liu, T.; Zhang, Z.; Kim, S.-H.; Pandey, A. Effect of Biochar on Emission, Maturity and Bacterial Dynamics during Sheep Manure Compositing. Renew. Energy 2020, 152, 421-429. [CrossRef]

44. Li, B.; Zhang, X.; Guo, F.; Wu, W.; Zhang, T. Characterization of Tetracycline Resistant Bacterial Community in Saline Activated Sludge Using Batch Stress Incubation With High-Throughput Sequencing Analysis. Water Res. 2013, 47, 4207-4216. [CrossRef] [PubMed]

45. Palisoc, M.; Guy, J.K.; Peacock, J.P.; Trinh, D.C.; Dodsworth, J.A.; Hedlund, B.P. Novel Thermophilic Cellulolytic Isolates Belonging to the Phylum Chloroflexi; Undergraduate Research, University Of Nevada: Las Vegas, NV, USA, 2011.

46. Franke-Whittle, I.H.; Knapp, B.A.; Fuchs, J.; Kaufmann, R.; Insam, H. Application of COMPOCHIP Microarray to Investigate the Bacterial Communities of Different Composts. Microb. Ecol. 2009, 57, 510-521. [CrossRef] [PubMed]

47. Al Atrouni, A.; Joly-Guillou, M.-L.; Hamze, M.; Kempf, M. Reservoirs of Non-Baumannii Acinetobacter Species. Front. Microbiol. 2016, 7, 49. [CrossRef]

48. Goldberg, J.B.; Hancock, R.E.; Parales, R.E.; Loper, J.; Cornelis, P. Pseudomonas 2007. J. Bacteriol. 2008, 190, 2649-2662. [CrossRef] [PubMed]

49. Xiang, W.; Gan, B.; Peng, W.; Jia, D.; Xie, L.; Huang, Z.; Jian, G. Screening and Identification of a Cellulose-Decomposing Strain Lysinibacillus Fusiformis. J. Environ. Eng. 2013, 7, 5041-5046.

50. Chantarasiri, A.; Boontanom, P.; Nuiplot, N.O. Isolation and Characterization of Lysinibacillus Sphaericus BR2308 from Coastal Wetland in Thailand for the Biodegradation of Lignin. Aquac. Aquar. Conserv. Legis. 2017, 10, $200-209$.

51. Ganguly, R.K.; Chakraborty, S.K. Assessment of Microbial Roles in the Bioconversion of Paper Mill Sludge through Vermicomposting. J. Environ. Health Sci. 2018, 16, 205-212. [CrossRef] [PubMed]

52. Huang, Y.; L, D.; Shah, G.M.; Chen, W.; Wang, W.; Xu, Y.; Huang, H. Hyperthermophilic Pretreatment Composting Significantly Accelerates Humic Substances Formation by Regulating Precursors Production and Microbial Communities. Waste Manag. 2019, 92, 89-96. [CrossRef]

53. Poomai, N.; Siripornadulsil, W.; Siripornadulsil, S. Cellulase Enzyme Production from Agricultural Waste by Acinetobacter Sp. KKU44. Adv. Mater. Res. 2014, 931-932, 1106-1110. [CrossRef]

54. Dexter, S.V.; Boopathy, R. Biodegradation of Phenol by Acinetobacter Tandoii Isolated from the Gut of the Termite. Environ. Sci. Pollut. Res. 2019, 26, 34067-34072. [CrossRef] [PubMed]

55. Wu, J.; Zhao, Y.; Qi, H.; Zhao, X.; Yang, T.; Du, Y.; Zhang, H.; Wei, Z. Identifying the Key Factors that Affect the Formation of Humic Substance during Different Materials Composting. Bioresour. Technol. 2017, 244, 1193-1196. [CrossRef]

56. Zhang, J.; Zeng, G.; Chen, Y.; Yu, M.; Yu, Z.; Hui, L.; Yu, Y.; Huang, H. Effects of Physico-Chemical Parameters on the Bacterial and Fungal Communities during Agricultural Waste Composting. Bioresour. Technol. 2011, 102, 2950-2956. [CrossRef] [PubMed]

57. Hu, T.; Wang, X.; Zhen, L.; Gu, J.; Zhang, K.; Wang, Q.; Ma, J.; Peng, H.; Lei, L.; Zhao, W. Effects of Inoculating with LignocelluloseDegrading Consortium on Cellulose-Degrading Genes and Fungal Community during Co-Composting of Spent Mushroom Substrate With Swine Manure. Bioresour. Technol. 2019, 291, 121876. [CrossRef] [PubMed]

58. Jiang, Z.; Lu, Y.; Xu, J.; Li, M.; Shan, G.; Li, Q. Exploring The Characteristics of Dissolved Organic Matter and Succession of Bacterial Community during Composting. Bioresour. Technol. 2019, 292, 121942. [CrossRef] [PubMed]

59. Zavrel, M.; Hoot, S.J.; White, T.C. Comparison of Sterol Import under Aerobic and Anaerobic Conditions in Three Fungal Species, Candida Albicans, Candida Glabrata, and Saccharomyces Cerevisiae. Eukaryot Cell. 2013, 12, 725-738. [CrossRef] [PubMed]

60. Kertesz, M.A.; Thai, M. Compost Bacteria and Fungi that Influence Growth and Development of Agaricus Bisporus and Other Commercial Mushrooms. Appl. Microbiol. Biotechnol. 2018, 102, 1639-1650. [CrossRef]

61. Ma, R.; Bai, Y.; Huang, H.; Luo, H.; Chen, S.; Fan, Y.; Cai, L.; Yao, B. Utility of Thermostable Xylanases of Mycothermus Thermophilus in Generating Prebiotic Xylooligosaccharides. J. Agric. Food Chem. 2017, 65, 1139-1145. [CrossRef]

62. Wang, X.; Kong, Z.; Wang, Y.; Wang, M.; Liu, D.; Shen, Q. Insights into the Functionality of Fungal Community during the Large Scale Aerobic Co-Composting Process of Swine Manure and Rice Straw. J. Environ. Manag. 2020, 270, 110958. [CrossRef]

63. Cannon, P.F.; Kirk, P.M. Fungal Families of the World; Cabi: Egham, UK, 2007.

64. Liu, C.; Liu, J.; Li, J.; He, H.; Peng, S.; Li, C.; Chen, Y. Removal of H2S by Co-Immobilized Bacteria and Fungi Biocatalysts in a Bio-Trickling Filter. Process. Saf. Environ. Prot. 2013, 91, 145-152. [CrossRef]

65. Meng, L.; Li, W.; Zhang, S.; Wu, C.; Lv, L. Feasibility of Co-Composting of Sewage Sludge, Spent Mushroom Substrate and Wheat Straw. Bioresour. Technol. 2017, 226, 39-45. [CrossRef] [PubMed] 